\title{
Hermann Graßmann - zwei sich unterscheidende Lebensläufe
}

\author{
Gert Schubring
}

Hermann Graßmann - Two Differing CVs

The mathematical and epistemological origins of Hermann Graßmann's innovative work have always attracted the interest of mathematicians and historians. Since Friedrich Engel's biography, a favourite source for these interpretations has been two curriculum vitae, which were, however, only known from several excerpts. The complete texts are edited here for the first time. They are presented and commented on in their respective contexts, namely the examinations required for a career as Gymnasium teacher and as Protestant pastor. Graßmann's relations to Schleiermacher's theology and to his philosophy, as well as Graßmann's philosophical and mathematical motivations, are discussed in the light of these two documents.

Keywords: Hermann Graßmann, curriculum vitae, Schleiermacher, philosophy of mathematics, theology studies, teacher examination

Schlüsse/wörter: Hermann Graßmann, Lebenslauf, Schleiermacher, Philosophie der Mathematik, Theologiestudium, Lehrerprüfung

\section{Zugänge zu Graßmann und Quellen}

Hermann Graßmann (1809-1877) hat stets eine Herausforderung für die Mathematik-Geschichtsschreibung gebildet: Ohne ein mathematisches Studium, praktisch als Autodidakt und ohne eine Position im akademischen Bereich hat er weitreichende Innovationen in der Mathematik eingeführt. Mit seinem Hauptwerk, der Linealen Ausdehnungslehre ([1844] 1862), hat er die Grundlagen für die Vektorrechnung und für die multilineare Algebra gelegt. Es ist nur zu verständlich, dass das Interesse der Historiker darauf gerichtet war, die Quellen für Graßmanns methodologische und konzeptuelle Innovationen zu ermitteln und die Einflüsse, die auf ihn gewirkt haben.

Das hat sich in seinem Fall als besonders schwierig herausgestellt. Einerseits hat zweifellos sein Vater Justus Graßmann als Mathematiklehrer Einfluss auf mehrere seiner mathematischen Begriffsbildungen ausgeübt, so mittels der kristallographischen Schriften auf Begriffe der Ausdehnungslehre (Scholz 1996: 43) und mittels der 
zahlentheoretischen Schriften, die ihm als Anregung zur Auseinandersetzung um die Dimensionen des mathematischen Raumbegriffs gedient haben können (siehe unten).

Andererseits entfällt in diesem Fall, wegen seiner rein autodidaktischen Studien, die sonst naheliegende Interpretation mittels der von ihm im Studium gehörten akademischen Lehrer, so dass die vielfach beliebten Zuschreibungen als „Schüler” und gar „Enkelschüler" bedeutender Professoren nicht möglich sind. Zudem hat Graßmann sich nirgends in seinen Schriften explizit zu Quellen und Einflüssen geäußert. Friedrich Engel, der als Teil der von ihm seit 1893 geleiteten Publikation der Gesammelten Werke Graßmanns 1911 dessen - inzwischen klassisch zu nennende - Biographie publiziert hat, gelang es schließlich, zwei relevante Dokumente $\mathrm{zu}$ finden. Deren Auswertung durch Engel hat seitdem wesentlich $\mathrm{zu}$ Versuchen gedient, um die Lücke zu füllen. Es handelt sich um zwei undatierte Lebensläufe, die Graßmann für zwei verschiedene Zwecke verfasst hatte.

Der erste, spätestens von Anfang Dezember 1831, war Teil seines Antrags an die wissenschaftliche Prüfungskommission Berlin, zur Prüfung pro facultate docendi zugelassen zu werden, also um Lehrer an einem preußischen Gymnasium zu werden. ${ }^{1}$ Der zweite, an das Konsistorium in Stettin, war Teil seiner Unterlagen für die Prüfung pro concionandi, also dem ersten Examen, um ein protestantischer Pfarrer zu werden. Er hat ihn laut Engel (Engel 1911: 8) am 3. April 1834 zusammen mit den Prüfungsarbeiten abgegeben. Er kann also Ende 1833/Anfang 1834 verfasst worden sein. Die Abschrift (siehe unten) datiert ihn auf den 23. März 1833.

Albert Lewis hat in seiner Studie von 1977, die es unternahm, die philosophischen Grundlagen von Graßmanns Begriffsbildungen zu analysieren, den zweiten Text als wichtige Quelle dargestellt, allerdings ohne seine Zwecksetzung zu erwähnen, und hat ihn offenbar deshalb als allgemeine Aussage des Autors über seine wissenschaftlichen Motivationen aufgefasst (Lewis 1977: 109 f.). Der zweite Lebenslauf hat auch dadurch mehr Prominenz erhalten, dass er in deutscher Sprache abgefasst ist, so dass Engel ihn viel umfangreicher wörtlich zitiert hat, während er vom ersten, in lateinischer Sprache geschriebenen nur einzelne Sätze zitiert beziehungsweise übersetzt, andere Teile dagegen nur referiert hat.

Bislang waren beide Lebensläufe lediglich aufgrund der Zitate und Exzerpte bekannt, die Engel daraus 1911 publiziert hat, indem er Textteile aus beiden Vorlagen als scheinbar gleichwertig mischte. Nach dem ersten Lebenslauf habe ich gesucht im Zusammenhang meiner aufwendigen Recherchen nach dem Verbleib der Akten 
der wissenschaftlichen Prüfungskommission Berlin, wobei es mir generell um die Dokumente der in Berlin geprüften Mathematiklehrer ging. Schließlich habe ich ermitteln können, dass die Berliner Prüfungsakten bis 1934 bei der Kommission selbst gelagert waren, dann aber an die Reichsstelle für Schulwesen abgegeben worden sind. Sie haben dort den Weltkrieg wohlbehalten überstanden, sind aber nach dem Juli 1945 auf rätselhafte Weise verschwunden (Schubring [1983: 23 f.] 1991: 222 f.). Bezüglich des zweiten Lebenslaufes teilte mir das Stadtarchiv von Szczecin mit, dass es zwar einen Aktenbestand des ehemaligen Konsistoriums besitzt, dass aber der Band mit der überlieferten Signatur zur Prüfung von Graßmann nicht mehr vorhanden ist. ${ }^{2}$

Trotzdem konnte ich schließlich 1985 fündig werden: Die Książnica Pomorska Szczecin, die zur Regionalbibliothek ausgebaute frühere Stadtbibliothek, besitzt Abschriften der beiden (undatierten) Lebensläufe. Es handelt sich um maschinenschriftliche Abschriften. Beide Abschriften sind sehr sorgfältig erstellt worden. So heißt es auf dem Deckblatt des ersten Lebenslaufs: „Mit dem Original verglichen! Stettin, 6.4. 1938. Eggebrecht”. Wilhelm Eggebrecht war ein leitender Mitarbeiter der Stadtbibliothek. ${ }^{3}$ Die gleiche Abschrift zeigt zugleich mit roter Tinte die Korrekturen, die der Prüfungskommissionsvorsitzende Köpke an der lateinischen Orthographie Graßmanns angebracht hat. Der Vermerk auf dem zweiten Lebenslauf lautet: „Aus den Akten des Stettiner Consistoriums Tit. IV, Sect. I, posit. 2a , Lit. G, Num. 19: Acta betreffend die Prüfung $u$. Beaufsichtigung des Kandidaten der Theologie Hermann Günther Graßmann aus Alt-Stettin”.

Engel hatte aus dem zweiten Lebenslauf die allgemeine Schlussfolgerung gezogen, der Theologe und Philosoph Friedrich Daniel Schleiermacher (1768-1834) habe den entscheidenden Einfluss nicht etwa auf Graßmanns theologische Auffassungen ausgeübt, sondern vorrangig auf seine mathematischen Begriffsbildungen (Engel 1911: 28). Lewis hat diese Interpretation noch verstärkt (Lewis 1977: 110) und in einer neueren Biographie wird Schleiermacher, mit seiner Dialektik, überhaupt zur Zentralfigur für Graßmanns intellektuelle Entwicklung und insbesondere für die Mathematik erhoben (Petsche 2006). Der Hinweis auf die Zwecksetzung des Lebenslaufs von 1833 (Schubring 1996: 60) wird dort emphatisch zurückgewiesen:

Bei der Lauterkeit des Gemütes, das [sic!] Hermann Graßmann Zeit seines Lebens an den Tag legte, erscheint mir ein solcher instrumenteller Umgang mit einem Lebenslauf zur Verbesserung der Chancen bei einer theologischen Prüfung nahezu undenkbar. (Petsche and Hans-Joachim 2006: 279, Fn. 148) 
Tatsächlich liegen jedoch zwei verschiedene Lebensläufe vor, mit unterschiedlichen Schwerpunkten, und somit ist eine vergleichende Analyse erforderlich, die natürlich nicht die „Lauterkeit” einer Person berührt, sondern die selbstverständliche hermeneutische Anforderung schon an jeden historischen Text darstellt; diese Notwendigkeit wird aber noch verstärkt, wenn sogar unterschiedlich gewichtete Äußerungen von derselben Person vorliegen. Ebenso wenig ehrenrührig ist es, wenn für zwei so differente Prüfungsziele und Lebensentwürfe wie die eines Gymnasiallehrers und den eines Pfarrers nicht übereinstimmende Texte verfasst wurden. Für diese notwendige Analyse werden hier erstmals die beiden Lebensläufe vollständig und im Original publiziert.

Deren kritische Analyse und der Vergleich mit anderen erhaltenen Dokumenten gehört zu den ersten Notwendigkeiten, bevor Aussagen aus den Lebensläufen verwertet werden können. So steht Graßmanns Aussage - am stärksten im Lebenslauf für die Lehrerprüfung -, er habe erst mit dem Studium der Theologie begonnen und habe sich dann der Philologie zugewandt in deutlichem Widerspruch dazu, dass er sich zunächst an der Universität Berlin in der Philosophischen Fakultät eingeschrieben hat und erst nach eineinviertel Jahren, zum Ende von 1828, zur Theologischen Fakultät gewechselt ist, am 21. Dezember $1828 .^{5}$ Die Angaben von Engel zu den von Graßmann an der Universität Berlin gehörten Vorlesungen stimmen mit den vom Quästor quittierten und von den Professoren testierten Angaben in Graßmanns Exmatrikel überein. ${ }^{6}$

\section{Vergleiche}

Vergleicht man nunmehr die beiden vollständigen Lebensläufe, so springt sofort der grundlegende strukturelle Unterschied beider Texte ins Auge. Während der Lebenslauf von 1831 ganz narrativ angelegt ist und aus zwei Hauptteilen besteht - einer Schilderung seiner Entwicklung im Laufe der Schulzeit und der anschließenden Beschreibung seiner Universitätsstudien und der folgenden Privatstudien -, beabsichtigt der Lebenslauf von 1833 eine systematische Darstellung der Entwicklung seiner religiösen Einstellungen und seiner theologischen Auffassungen. Graßmann hat diese Entwicklung in drei Stufen gegliedert: Die „Zeit des religiösen Schlummers” (bis 1823), der ,streng orthodoxen Ansicht vom Christentum” (bis etwa 1829) und schließlich dem Vorherrschen der "Schleiermacherschen Ansicht". 
Das Verständnis des ersten Lebenslaufs erfordert eine Analyse der Anforderungen an die Lehrerprüfung in Preußen und deren Veränderungen. Mit dem königlichen Lehrerbildungsedikt von 1810 ist in Preußen erstmals eine wissenschaftliche Lehrerbildung begründet worden: Nach einem dreijährigen wissenschaftlichen Studium erfolgte die Prüfung pro facultate docendi, also das allgemeine Examen für die Lehrbefähigung, vor einem staatlichen Prüfungsgremium, vorwiegend aus Wissenschaftlern - zunächst den wissenschaftlichen Deputationen, ab 1817 den wissenschaftlichen Prüfungskommissionen (wPK). Die Prüfung erfolgte in den drei Hauptfächern des Gymnasiums: Philologie, Geschichte und Geographie sowie Mathematik und Naturwissenschaften. Die mit den Prüfungen beabsichtigte Konzeption des Gymnasiallehrers war die eines allgemein gebildeten Fachlehrers: Neben der vertieften Prüfung in den Fächern, denen der Kandidat ,sich vorzüglich gewidmet hat", waren Prüfungen in den anderen Hauptfächern vorgesehen, um eine fachliche Einseitigkeit zu verhindern. Es war ein Bruch mit dieser neuhumanistischen Bildungskonzeption, als 1824 vom Kultusministerium die erste größere Änderung der Prüfungsordnung von 1810 durchgesetzt wurde: Aus politischen Gründen wurde als weiteres Prüfungsfach die Theologie eingeführt, für die schließlich auch eine weitere Prüferposition in den wPKs eingesetzt wurde. Es war diese, 1824 geänderte Prüfungsordnung von 1810, auf die hin Graßmann sein dreijähriges Studium in Berlin, von 1827 bis 1830, ausgerichtet hatte.

Er konnte nicht ahnen, dass im April 1831 eine neue Prüfungsordnung vom Ministerium in Kraft gesetzt würde, die gegenüber den noch sehr allgemein gehaltenen Formulierungen von 1810 nunmehr sehr ausführliche und genaue Bestimmungen für alle Prüfungsfächer enthielt. So wurde jetzt für alle Fächer festgelegt, welche Kenntnisse Lehrer dieser Fächer für untere Klassen, für mittlere und für obere beherrschen sollten, sowie auch die Anforderungen für allgemeine Bildung. Das galt auch für die Prüfung in ,"Theologie und hebräischer Sprache”. Zudem definierte die Ordnung die zu erteilenden Lehrbefähigungen neu. Es wurden die zwei Grade der bedingten und der unbedingten facultas eingeführt: Die unbedingte facultas erforderte, in mindestens einem Hauptfach in den obersten Klassen unterrichten zu können und mit allen anderen Prüfungsfächern soweit bekannt zu sein, ,um ihre relative Wichtigkeit richtig würdigen und auf die Gesamtbildung der Schüler wohltätig einwirken zu können" (LPO \$ 16). Die bedingte facultas erhielten dagegen die Prüflinge, die statt für die obersten „nur” für die unteren und mittleren Klassen für befähigt erklärt worden waren (LPO \$ 22). 
Für die Meldung zur Prüfung wurde ein in lateinischer Sprache verfasster Lebenslauf gefordert. Er sollte neben der allgemeinen Darstellung der bisherigen Biographie eine genaue Darstellung der universitären Studien enthalten, aus der ersichtlich sein sollte, in welchen Fächern der Kandidat sich die meisten Kenntnisse zutraute (LPO $\$$ 6). Der Lebenslauf musste schon deswegen ausführlich sein, weil erst aufgrund dieses zweiten Teils die Prüfungskommission die Anzahl und die fachliche Ausrichtung der zu erstellenden schriftlichen Aufgaben festlegte (LPO $\mathbb{9}$ ).

Da auch ab 1831 Theologie ein Prüfungsfach war, hat Graßmann im ersten Lebenslauf seine theologischen Studien erwähnt, aber nicht so intensiv, um darin sein Hauptfach zu deklarieren. Schleiermachers Vorlesungen hat er in diesem Zusammenhang als von ihm viel besucht angeführt; er zeigte damit eine Übereinstimmung mit der Prüfungsforderung, eine Kenntnis der ,allgemeinen Regeln der biblischen Kritik und Hermeneutik" nachzuweisen $(\text { LPO } \$ 21)^{7}$; im Weiterführen der Hermeneutik hat eine der wichtigsten wissenschaftlichen Leistungen von Schleiermacher bestanden. Als seine Hauptstudien, denen er sich nach Abwendung vom Theologie-Studium zugewendet habe, hat Graßmann die Philologie erklärt und deren Studien sehr detailliert beschrieben. Von den drei Hauptfächern des Gymnasiums hat er im Lebenslauf für die Lehrerprüfung ganz intensiv das universitäre Studium der Philologie hervorgehoben, während er Mathematik und Naturwissenschaften wesentlich kürzer und nur als Gegenstand von Selbststudium darstellte; Studien in Geschichte hat er dagegen nur mit zwei Sätzen kurz gestreift.

Die ihm gestellten schriftlichen Aufgaben entsprachen sehr genau der Darstellung seiner Studien: Neben der üblichen Aufgabe zur allgemeinen Pädagogik erhielt er Aufgaben zur klassischen Philologie und zur Mathematik. In der mündlichen Prüfung wurde er darüber hinaus, gemäß der Prüfungsordnung, auch in den Fächern geprüft, die keine Schwerpunkte des Studiums und des Selbststudiums gewesen waren: in Geschichte, Naturlehre, Philosophie und Theologie (Engel 1911: 39 f.). Obwohl Graßmann in keinem der Prüfungsfächer eine Befähigung zum Unterricht auch in den oberen Klassen erreicht hatte, wurde ihm - entgegen der neuen Prüfungsordnung - die unbedingte facultas erteilt. ${ }^{8} \mathrm{Um}$ auch in oberen Klassen unterrichten zu können, hat er sich 1840, mit Erfolg, einer Nachprüfung unterzogen. Das Ergebnis der mit Hebräisch verbundenen Prüfung von 1831 in Theologie war, dass er aufgrund seiner Kenntnisse der hebräischen Grammatik zum Unterricht der hebräischen Sprache sowie zum Religionsunter- 
richt in den unteren Klassen befähigt erklärt wurde. Eine Befähigung für untere Klassen bedeutete nach der damaligen Wissenshierarchie einen relativ geringen Kenntnisstand.

\section{Die Rolle Schleiermachers}

Der zweite Lebenslauf - in seiner vollständigen Form und nicht in einzelne Zitate aufgelöst sowie mit Texten aus dem anderen Lebenslauf vermischt - zeigt eine prinzipiell andere Anlage. Er ist keine Schilderung des ,äußeren” Lebens, er gibt auch keine Darstellung von Lern- und Studieninhalten. In krassem Gegensatz zum ersten Lebenslauf wird das Studium der Philologie sogar zur Nebensache erklärt, die er ,zuletzt auch” studiert habe. Dieser Text bildet dagegen eine Reflexion über das „,innere” Leben: Das bestimmende Thema in Graßmanns Lebenslauf für die erste Pfarrer-Prüfung bildet sein Übergang vom orthodoxen Luthertum zur aufgeklärten Auffassung Schleiermachers.

Den theologischen Kern in diesen Selbstreflexionen bildet die Auseinandersetzung mit der Gnadenlehre und dort insbesondere die eigene aktive Herausbildung - oder Erregung, in Schleiermachers Termini - des ,frommen Selbstbewußtseins” als Voraussetzung zum Erlangen der Gnade. Die erste von Graßmann geschilderte Lebensphase ist die der eigenen Inaktivität, die daher dem religiösen Schlummer entspricht. Charakteristisch sind daher die Illusionen über das idyllische Leben von Landpfarrern. Die zweite Phase, mit der Graßmann sein eigenes Aktiv-Werden schildert, entspricht daher dem Erwecken eines religiösen Sinnes. Allerdings ist sie noch vom Unverständnis des protestantischen Gnadenkonzepts geprägt: Graßmann schreibt sich ,,anti-lutherische” Auffassungen zu, indem er auf ,äußere Werke” setzte.

In der Tat bildete die Gnadenlehre den Kern der streng lutherischen Orthodoxie (vgl. Greschat 1997: 82 f.). Bekanntlich war es ein Ausgangspunkt für Luthers Reformation gewesen, auf „sola gratia” - allein durch die Gnade - zu bestehen, im Gegensatz zum Erwerb der Gnade durch äußere Werke, etwa den Ablasshandel. Wie Ernst Troeltsch hervorgehoben hat, war allerdings in der ,altprotestantischen”, also orthodoxen Dogmatik die Gnade zu einem ,sekundären Prinzip in Gottes Wesen” geworden (Troeltsch 1910: 1472). Graßmann benennt einen Kernpunkt dieser orthodoxen Dogmatik, den er in seiner zweiten Entwicklungsstufe noch als zentralen Glaubensinhalt aufgefasst hatte: die Ermöglichung der Gnade durch stellvertretendes Strafleiden Christi, nämlich vor 
allem durch dessen Kreuzestod (ebd.). Es war erst die moderne Auffassung Schleiermachers, die in Auflösung dieser Lehre den Gnadenbegriff wieder zum Kernpunkt erhoben hatte. Dadurch ermöglicht wurde die „Heraushebung des Willens- und Freiheitsgedankens in Gott, wie das durch Luther und Kant vollzogen worden ist" (ebd.).

Schleiermacher hat die moderne Form protestantischer Theologie in seinem klassischen Werk formuliert, das aus Vorlesungen zur Dogmatik hervorgegangen ist: Der Christliche Glaube, zuerst 1821/22 publiziert, und in überarbeiteter Form 1830/31. Religion hat er dort gefasst als „,frommes Selbstbewußtsein”, und Gnade hat er - ausgehend vom Spannungsgegensatz von Sünde und Gnade als das Erreichen der Übereinstimmung, der Gemeinschaft mit der Vollkommenheit und Seligkeit des Erlösers verstanden (Schleiermacher 2003). Zentral war daher für das Erlangen von Glauben und damit auch der Gnade Gottes das $\mathrm{zu}$ erregende fromme Selbstbewusstsein. Die Neubestimmung von Religion mittels dieses von ihm begründeten Begriffs und damit als etwas Subjektives hat Schleiermacher der höhnenden Polemik Hegels ausgesetzt und damit ihre Gegnerschaft unversöhnlich gemacht. Ganz in Übereinstimmung mit der für die neuhumanistischen Reformen kennzeichnenden Konzeption der Selbsttätigkeit, war das fromme Selbstbewusstsein als entscheidende Verwirklichung des ,sittlichen Freiheitsgeistes" verstanden worden (Troeltsch 1910: 1471). Den Gedanken der Werkgerechtigkeit hat Schleiermacher abgelehnt; protestantische Christen leben durch die Rechtfertigung sola fide (Nowak 2001: 255).

Graßmanns Lebenslauf dokumentiert seine allmähliche Aneignung dieser Konzepte. Wie er insbesondere im Schlussteil dargelegt hat, zielte er - anstatt des Handelns nach ,äusserem Vorsatz” nunmehr auf „Freude an der Tätigkeit”, auf Erzielung einer „höheren Kraft” - zur Umwandlung des ,inneren Lebens”.

Für ausführlichere Darstellungen seiner theologischen Ansichten hat Graßmann dort auf seine schriftlichen Prüfungsarbeiten verwiesen. Trotz dieses expliziten Hinweises ist Engel dem nicht nachgegangen (vgl. Engel 1911: 44), so dass wir heute leider keinen Zugang mehr zu diesen Darstellungen haben. Auch über die Aussagen in Graßmanns zweiter theologischer Prüfung 1839 hat Engel nichts übermittelt. Der Lebenslauf von 1833 war ja auf einen Aspekt, den der Herausbildung des frommen Selbstbewusstseins konzentriert. Graßmann hat daher keine Stellungnahmen zu den damals kontroversen Debatten über Pietismus, Rationalismus und die nach 1800 einsetzenden Erweckungsbewegungen aufgenommen 
(Greschat 1997: 92 f., 149 f.); diese dürften sich in den einzelnen Prüfungsarbeiten finden. Wegen seiner zahlreichen Verwandten, die lokal und regional im kirchlichen Dienst waren, wird Graßmann gut unterrichtet gewesen sein über die Haltung des Konsistoriums Stettin zu Schleiermachers Theologie. Die Prüfung wurde mit „Gut Bestanden" bewertet (Engel 1911: 44).

Schleiermacher war über seine Leistungen als Reformer der protestantischen Theologie hinaus auch insofern eine Ausnahmepersönlichkeit, als er nicht nur ein innovativer Theoretiker in Theologie, Philosophie und Pädagogik war, sondern zugleich ein hervorragender Praktiker des Predigtamtes. Alle Berichte stimmen darin überein, ihn als „begnadeten Kanzelredner” zu charakterisieren - und zudem ohne allen rhetorischen Pomp (vgl. Nowak 2001: 390 f.). Auch Graßmann ist von Schleiermachers Predigten fasziniert und dadurch auf das Praktisch-Werden orientiert worden; er hat daher auch die Gestaltung des „Positiven” als wichtiges Element seiner dritten religiösen Phase hervorgehoben.

Die bisherige überwiegende Tendenz, den Einfluss Schleiermachers auf Graßmann nicht in den theologischen Konzeptionen zu suchen, sondern - aufgrund der von Engel aufbereiteten einzelnen Zitate aus den Lebensläufen - in Schleiermachers philosophischem Werk Dialektik, 1839 posthum erschienen als Bearbeitung einer Vorlesungsmitschrift, beruht offenbar auf einem Missverständnis. Graßmann hat die Dialektik-Vorlesung in seinem zweiten Semester gehört, aber nach eigenem Bekunden nicht verstanden. Die Konzentration der Interpretation auf Schleiermachers Dialektik ist offenbar von dem Missverständnis bewirkt, „Dialektik” im seit Hegel geläufigen Sinne zu verstehen. Tatsächlich hat aber Schleiermacher eine ganz unabhängige und charakteristische Auffassung von Dialektik vertreten - nämlich in der ursprünglichen griechischen Bedeutung: als dialogisches Verfahren, das zur Ermittlung der Sicherheit des in Frage stehenden Wissens führen soll: „Da das wirkliche Wissen immer nur in streitigem Zustand vorkommt, ist die Lehre vom Wissen nur in der Kunstlehre der Dialektik als Lehre von der kunstmäßigen Bildung der Begriffe, der Urteile und ihres Zusammenhanges zu entfalten." (Kasprzik, zit. n. Jüngel 2004: 912) Die Methode besteht darin, vom Alltagswissen auszugehen und sicheres Wissen anzuzielen durch Dialog der Partner; sie impliziert auch zu klären, was „Wissen” bedeutet und wie Denken und Erfahrung aufeinander bezogen sind (vgl. Röd 1974: 116 f.).

In der Tat hat Victor Schlegel - Graßmanns erster Biograph, der ihn zugleich intensiv kannte aufgrund mehrjähriger Zusammenarbeit am Gymnasium Stettin - eine ganz andere Beurteilung 
von Schleiermachers Bedeutung für Graßmann gegeben. Er hat zwar auch Schleiermacher einen beträchtlichen Einfluss zugeschrieben, aber die Lektüre der Dialektik als eine Entfernung von der Mathematik berichtet. Gemäß Schlegel hat Graßmann nach Fertigstellung seiner mathematisch bereits bahnbrechenden Prüfungsarbeit von 1840 über Ebbe und Flut nicht die Ausarbeitung seiner neuen mathematischen Konzepte fortgesetzt, sondern hat sich nach der nunmehrigen Lektüre der Dialektik Schleiermachers von der Mathematik ab- und sprachphilosophischen Untersuchungen zugewandt:

Die kurz zuvor veröffentlichte Dialektik seines verehrten Meisters Schleiermacher zog ihn zu mächtig an und riss ihn vorübergehend in eine neue Strömung, in der er gemeinsam mit seinem Bruder Robert arbeitete. So wurde im nächsten Jahre (1841) eine philosophische Sprachlehre ausgearbeitet, deren Resultate er in einem ,Grundriss der deutschen Sprachlehre' und einem ,Leitfaden für den deutschen Unterricht' niederlegte (publiziert 1842). (Schlegel 1878: 4f.)

„Endlich”, wie Schlegel sagt, sei Graßmann um Ostern 1842 mit ganzer Kraft zur Mathematik zurückgekehrt (ebd.).

Wenn daher die Indizien nicht für eine erhebliche Wirkung von Schleiermachers Dialektik auf Graßmanns mathematische Innovationen sprechen, stellt sich die Eingangsfrage nach konzeptionellen und epistemologischen Hintergründen und Einflüssen erneut. Dazu lässt sich als bisheriger Stand meiner Forschungen resümieren: Schleiermachers großer Konkurrent als führender Philosoph, Hegel, kommt nicht in Frage. „Hegel und seine Schule” sind die einzigen von Graßmann angeführten philosophischen Zeitgenossen - und zwar grundsätzlich ablehnend: wegen ihrer Obskurität und Willkürlichkeit (Graßmann 1894: 15). Es ist dagegen lohnend, direkt von Graßmanns mathematischen Ansätzen auszugehen. Als mathematische Motive für seine Ausdehnungslehre hat Graßmann einerseits den Begriff des Produkts in der Geometrie genannt, wie ihn sein Vater entwickelt hatte: für den Produktbegriff hatte dieser sich für eine algebraische Interpretation geometrischer Operationen entschieden. Andererseits hat Graßmann als seine Hauptmotivation die Betrachtung negativer Größen in der Geometrie genannt. Den Ursprung seiner Konzepte bildete also dasselbe Begriffsfeld, das schon die Mathematiker Carnot, Argand, Bellavitis und Hamilton angeregt hatte. Die Ansätze Graßmanns lassen sich daher gut verorten in den zeitgenössischen Grundlagen-Auseinandersetzungen zwischen geometrischer und algebraischer Analysis (Schubring 2003).

Vom Gesichtspunkt einer Philosophie der Mathematik her ist der relevanteste Ansatz Graßmanns sein Aufbau der Mathematik, 
indem er von einer allgemeinen Formenlehre ausging. Graßmann selbst hat sich als Propagator der Neuorientierung der Mathematik als reiner Mathematik verstanden und die Formenlehre als deren Grundlagendisziplin entwickelt - während er Geometrie und Mechanik als Anwendungen nicht zur reinen Mathematik zählte.

In der Formenlehre ging es darum, Gesetze von Verknüpfungen - oder Operationen - ganz allgemein aufzudecken. Graßmann hat hier erstens zwischen synthetischen und - diese aufhebenden analytischen Verknüpfungen unterschieden, sowie zwischen Verknüpfungen verschiedener Stufen. Als mögliche Eigenschaften der Verknüpfungen untersuchte er Assoziativität, Kommutativität und Distributivität. Im Anschluss an den allgemeinen Teil erfolgte die Deutung der synthetischen Verknüpfung erster Stufe als Addition und der analytischen als Subtraktion sowie der entsprechenden Verknüpfungen der zweiten Stufe als Multiplikation beziehungsweise Division. Wie Graßmann betonte, sind die Kommutativität und Assoziativität nicht schon im allgemeinen Begriff der Verknüpfung der zweiten Stufe angelegt, so dass in der neuen Ausdehnungslehre Arten der Multiplikation auftreten werden, in denen die Kommutativität nicht gilt (Schubring/Freguglia 2004).

Der einzige zeitgenössische Ansatz in der Philosophie zu einer solchen neuen Grundlagendisziplin liegt bei Jacob F. Fries (1773-1843) vor, der diese Konzeption in seinem Buch Die mathematische Naturphilosophie 1822 publiziert hat. Graßmanns Vater Justus hatte in seiner wichtigen zahlentheoretischen Arbeit von 1827 eine Konzeption von Fries diskutiert, sie aber abgelehnt: Fries' Auffassung von einer nicht begrenzten Anzahl von Dimensionen „Stufen” - in der Verknüpfung von Operationen (Fries 1822: 97). Während Justus sich auf die traditionelle Anzahl von drei Dimensionen beschränkt hatte (Graßmann 1827: 35), spricht viel dafür, dass diese Debatte eine Anregung für Hermann gewesen ist, diese Beschränkung - Fries folgend - fallen zu lassen.

Fries' zentrales Ziel war es, eine Philosophie der reinen Mathematik zu entwickeln und untersuchte dafür die Gesetze der „Verknüpfungsformen”. Für Fries war die Mathematik das vollständige System aller mathematischen Formen. Die reine Mathematik finde ihren Haupterfolg in der Aufdeckung der reinen Formen der Zusammensetzung (Fries 1822: 49 f.). Es war Fries, der damit als erster eine unabhängige Grundlagendisziplin entwickelt hat, die die Verknüpfungsformen der traditionellen Teildisziplinen begründet (Schubring 1990). Die Entsprechung zwischen dieser von Fries "Syntaktik” genannten neuen Basisdisziplin und der Formenlehre Graßmanns spricht für einen konkreten Einfluss. 


\title{
Die beiden Fundstücke
}

\author{
Die Lehrerprüfung
}

\author{
Abschrift $^{9}$ \\ Curriculum vitae et studiorum ratio \\ Herm. Graßmann
}

Quum de me ipso mihi sit scribendum, multas undique difficultates mihi obstructas esse video. Nam ne dicam, nos nostri nec diligentes esse exploratores, nec severos aestimatores, illa ipsa aetas, qua primum studia incitabantur, et mores in animo tanquam in cera sigillum imprimebantur, tam longe est remota, ut vix eam intueri nedum perspicere possimus. Huc accedunt propria quaedam hujus, qua nunc sum, aetatis impedimenta.

Nam quem ad modum in humanarum rerum memoria ea tempora, quae subitis motibus coortis quasi citata feruntur, et sua sponte oculorum aciem fere fugiunt, et vix prius perspici possunt, quam sedatis illis motibus homines quum fructus ex illis temporibus redundantes, tum vero ipsam eorum notitiam percipiant: ita suum quisque ingenium suamque naturam tum minime novit, quum in explicandis facultatibus versatur, multo autem clarius se ipsum perspicere solet, quum refrigescente juvenili ardore, ad constantiam quandam pervenit.

Natus Sedini anno MDCCCIX, patre utens I. Grassmanno, professore Gymnasii Sedinensis, nulla re videbar carere, quae ad facultates insitas et eliciendas et augendas faceret. $\mathrm{NeC}$ tamen, tantam discendi copiam jam puer nactus, ullum fere ingenii
Da ich über mich selbst schreiben soll, merke ich, dass sich mir von allen Seiten viele Schwierigkeiten entgegenstellen. Denn ich will nicht sagen, dass wir nicht sorgfältige Erforscher unserer selbst und nicht strenge Beurteiler sind, doch jenes Alter selbst, in welchem zuerst unsere Neigungen angestachelt und die Sitten in unserem Geist so wie in Siegelwachs gedruckt wurden, ist so weit entfernt, dass wir es kaum wahrnehmen geschweige denn durchschauen können. Hierzu treten gewisse eigentümliche Schwierigkeiten dieser Lebenssituation, in der ich jetzt bin.

Denn bis zu welcher Grenze in der Erinnerung der menschlichen Dinge reichen diese Zeiten, die durch plötzlich hervortretende Bewegungen wie angetrieben werden und aus eigenem Antrieb die Scharfsicht der Augen meistens fliehen und kaum früher erkannt werden können, als die Menschen nach Beruhigung jener Bewegungen, wennschon die Früchte aus jenen Zeiten überströmen, dann aber doch besonders die Kenntnis selbst von sich wahrnehmen: So versteht jeder seinen Charakter und seine Naturanlage dann sehr wenig, wenn er sich in den zu erklärenden Anlagen befindet, pflegt sich selbst aber um vieles klarer zu durchschauen, wenn er nach Erkalten der jugendlichen Glut zu einer gewissen Beständigkeit gelangt.

Geboren in Stettin im Jahre 1809, mich eines Vaters erfreuend, J. Graßmann, der Professor am Stettiner Gymnasium war, schien mir nichts zu fehlen, was zu den angeborenen Fähigkeiten noch zu fördernde und zu vermehrende 
specimen edebam. Memoria enim difficillima simul erat et perfidissima, ut, quum ad octo singulos versus ediscendos tres fere horae opus essent, ne tum quidem illi in memoria haererent, sed proximo quoque tempore exciderent.
Nec tamen pater hac memoriae imbecillitate perspecta impelli poterat, de institutione puerili ut quidquam mutaret, sed probe sciens, eandem fere informationem puerilem, quasi fundamentum quoddam commune, omni vitae rationi substratam esse, idcircoque omnino integrum mihi relinquens, qualem quum mei judicii forem, vitae cusum ${ }^{10}$ tenere vellem, illis doctrinis, quibus puerilis aetas impertiri solet, me erudiendum curavit. Ac saepe dicere solebat, suas cuique facultates vitae provinciam decernere, se aequo animo laturum esse, si vel hortulani vel operarii.officiis aliquando fungi velim, modo eam vitae rationem deligerem, quae et viribus par esset et quam cum mea laude et hominum commodo sequi possem. machte. Und dennoch, obwohl ich schon als Knabe eine solche Fülle zu lernen erlangt hatte, brachte ich fast keine Probe von Begabung zum vorschein. Mein Gedächtnis war nämlich zugleich äußerst schwierig und unzuverlässig, so dass, nachdem zum Lernen von acht einzelnen versen fast drei Stunden nötig waren, dann nicht einmal jene im Gedächtnis hafteten, sondern auch in nächster Zeit wieder entfielen.

Sein Vater habe diese Schwäche des Gedächtnisses wohl bemerkt, habe aber darauf bestanden, daß der Knabe ebenso wie die andern so lange an allem Unterricht teilnehme, bis er selbst fähig sei, zu beurteilen, welche Laufbahn für inn passend sei. Der Vater habe oft geäußert, er werde es mit Gleichmut ertragen, sollte auch sein Sohn Gärtner oder Handwerker werden, wofern er nur einen seinen Kräften angemessenen Beruf wähle und diesen mit Ehren und zu Nutzen seiner Mitmenschen ausfülle.

(Engel 1911: 8-9)

Sed quo fieri solet, ut filii parentum et cognatorum negotia maxime ad ament, id mihi quoque cognati. Nam et cognati prope omnes Theologiae se dederant, et pater ipse antea quidem eam coluerat, deinde tamen cum mathematico studio commutaverat. Huc accedebat, quod vitam rusticam sedem, ac domicilium felicitatis esse ratus, concionatorem inter homines incorruptos versantem, cum iis vitae societate ad unam quasi familiam conjunctum, vitam beatissimam ab negotiis et placidissimam agere in animum induxi. Vitam autem desidem ${ }^{11}$, ab negotiis quam maxime vacuam, opibus et gratia affluentem, summum habebam bonum. Quae quidem beatae vitae imago semper animo obversabatur et in pueritiae somniis et cogitationibus primas partes agebat. Nam pueritia mea, somni instar, vanis somniis et somniculosis cogitationibus erat repleta, quas inertia excitabat, amor mei alebat. In iis quod maxime exoptabam, quod summo amore amplectebar, animo repraesentare solebam. Illa somnia animi nervos carpebant, gravissimum quodque 
studium odiosum reddebant, a vitae societate me avocabant, mores effeminabant, ingenium opprimebant. ${ }^{12}$

Propter ea nulla prope re admodum delectabar vel movebar, in ludis aequalium secundas agere partes, eos semper sequi, mea sponte nihil suscipere, a sodalibus segregatus dormitare, insolita quaque re et subita terreri, in majorum natu societate timide refugere. Quod solum fere voluptatem quandam afferebat, erant ludi quidam cum minoribus natu instituti, quibus ego eos nunc joco nunc serio docebam, et ita eorum animos intentos tenebam, ut et summum silentium agerent, et saepe illum ludum renovare cuperent. Unde pater facultatem quandam docendi conjiciens, me aliquando hoc docendi munus suscepturum esse putabat. Ad pietatem erga Deum, quae una vis animum interdum movebat jam prope ab incunabulis pia parentum educatione informatus sum.

Verumne haec quidem animum exsomniis illis eripere et adstrenue agendum inflammare potuit.
Beim Zusammensein mit Älteren habe er sich immer scheu zurückgezogen. Wahres vergnügen habe er nur an gewissen Spielen gefunden, die er mit jüngeren Kindern veranstaltete; dabei habe er diese bald im scherze bald im Ernste unterrichtet und sie so zu fesseln gewußt, daß sie ganz Ohr waren und oft nach Wiederholung des Spiels verlangten. Sein vater habe daraus auf das Vorhandensein einer gewissen Lehrbegabung geschlossen und gemeint, daß ein Lehrer in ihm stecke. Sonst habe höchstens die Ehrfurcht vor Gott, die seine frommen Eltern ihm früh eingepflanzt hätten, ihm das Herz bewegt, aber auch diese sei unvermögend gewesen, ihn seinen Träumereien zu entreißen. (Engel 1911: 9)

Sed jam pueritiae tenebris relictis, ad juvenilem aetatem accedam. Quam a quo termino coepisse dicam dubitare non possum. Nam ut pueriliam somno similem fuisse, ita juventutem in eo versatam esse et adhuc versari dico, ut ex illo somno expergefiam. Paternis cohortationibus sodalium illusionibus, piis concionatris in consecrando admonitionibus suscitatus, subito me longo quodam reterno oppressum jacuisse cognovi, nec quidquam antiquius habui, quam, ut sordes menti inhaerescentes eluerem et delerem. Quod consilium in dies magis confirmatum eo denique abire videbatur, ut animum prope in contrariam portem, ex desidiis ad vigorem, ex somniis ad alacritatem, ex frigido languore ad ardorem, ex otio moli ad negotia et labores compellere vellem.

Memoria repente expergiscere visa est. Nam quum mentem adsidue ad rem ipsam, quam memoriae mandare vellem, intentam, tenerem, eam opinione celerius percipere solebam
Auch da erzählt Graßmann, sein Gedächtnis sei mit einem Male erwacht; denn indem er seinen Geist angestrengt mit den Dingen beschäftigt habe, die er sich einprägen wollte, habe er diese schneller behalten. 
Nec tamen ad singula verba ediscenda vel ad locum memoriae infigendum unquam accommodatus fui.

Commentationes, quae nobis Germanice scribendae essent, antea optimo jure vituperatae, inde ab eo tempore laudem aliquam consecutae sunt, quasi tum primum cogitare coeperim.
Er fügt aber hinzu, er sei doch niemals geschickt geworden, einzelne Wörter auswendig zu lernen oder einen ganzen Abschnitt im Gedächtnis zu behalten. (Engel 1911: 12)

In der That wurden meine deutschen Aufsätze, die bis dahin sich nur gerechten Tadel zugezogen, seitdem meist von den Lehrern gelobt; als ob ich damals erst zu denken angefangen hätte. ${ }^{13}$

Animus, qui antea somno abrutus, propter id ipsum moesti ${ }^{14}$ aliquid habuerat, idem tum primum hilaritate quadam erat erectus. Quo eventu magis etiam confirmatus, omnes facultates in animi vigore positas esse existimavi, et unam quamque rem eo facilius percipi, quo alacrius animus in ea percipienda versaretur; fortunam ex hominis voluntate totam pendere, ita ut homo fortunam, non fortuna hominem fingeret.

Sed quamquam tota animi natura hoc consilio et hoc studio immutata est, tamen nimis discrepabat haec ratio, quam inieram, $\mathrm{ab}$ insita animi indole, quam ut eam constanter tueri potuissem.

Ita, quod cum natura ipsa pugnabam, saepe factum est, ut animus, supra modum suum adstrictus, deinde relaxatus torperet. Mala ex puerili inertia nata, quoties rationis aciem non fugiebant, non evellebantur illa quidem, sed tamen reprimebantur
Ferner sagt er, das Erwachen aus dem früheren Schlafzustande und die ganze damit zusammenhängende veränderung sei nur erreicht worden durch einen beständigen Kampf mit der ihm angeborenen Charakteranlage und bei diesem Kampfe seien Rückfälle in die alten Träumereien nicht ausgeblieben, denn diese seien eben nicht ausgerottet gewesen, sondern nur zurückgedrängt. (Engel 1911: 12)

Verum multo saepius fieri solebat, ut illa in ignotos animi recessus irreperent, ibique tenebris suis obtecta optimam quamque rem gestam inquinarent, sanctissimam quamque cogitationem pestifero suo spiritu afflarent.

Quod ad studia attinet, nihil egregie praeter cetera studebam, omnia tamen mediocriter, ita ut nec vituperationem, nec insignem tandem ${ }^{15}$ a praeceptoribus mihi compararem.
So habe er auch kein Fach mit besondrer vorliebe und mit Auszeichnung betrieben, wohl aber alle ziemlich befriedigend, so daß er sich weder den Tadel seiner Lehrer zugezogen noch hervorragendes Lob verdient habe. (Engel 1911: 12) 
Unde intelligi potest, naturalem indolem plus valuisse quam operam et industriam

Quum in hoc loco essem, non alienum erit commemorare, quam Latine scribendi viam tunc inierim. Quum enim praeceptor omne Latine scribendi consilium ad Ciceronis normam dirigendum esse censeret, et copiam verborum. Latino quodam colore ornatam desideraret: primum quidem Ciceronem totum legendo percurrere statui, deinde autem, paucis ejus libris perlectis, laboris hujus molestia deterritus, Ciceronis orationem unam alteramque legi, et, nihil curans sensum, nihil reram dicendi elegantiam, nihil adeo verborum constructionem, adea tantum verba attendi, quae particulis: et, ac etc. conjuncta essent. Ea signo notata in commentationem Latinam, quae nobis esset scribenda, ad unum fere omnia deinceps transferebam. Hoc modo me ne gustare quidem potuisse veram linguae indolem, perspicuum est
Als charakteristisch führt er dann noch die Art an, wie er das Lateinischschreiben betrieben habe. Weil nämlich der Lehrer Cicero-manisches Latein verlangte und die rechte, lateinisch gefärbte Wortfülle vermißte, so habe er zuerst beschlossen, den ganzen Cicero durchzulesen. Da ihm aber diese Arbeit bald lästig geworden sei, so habe er ein paar Reden durchstudiert und dabei, ohne auf den Sinn und die Eleganz des Ausdruckes, ja auch nur auf die Konstruktion der Wörter zu achten, sich bloß um die Wörter gekümmert, die durch Partikeln wie et, ac u. dg/. verbunden waren, diese habe er dann in einem lateinischen Aufsatze fast alle angebracht; selbstverständlich habe er auf diese weise den Geist der Sprache nicht fühlen können. (Engel 1911: 12-13)

Iam accedo ad illam vitae partem, quae ad mores conformandos et ad facultates excitandas et excolendas plurimum facere solet: ad vitam Academicam, quam quidem totam Berolini peregi Theologiae; sicut puer constitueram, operam navabam.

De studiorum ratione nunc primum erit dicendum, quum [antea studia ex praeceptorum vel jussu vel auctoritate penderent. Sed ut vere confitear, etiam illo tempore prófessorum auctoritati plurimum tribui, ita ut magis mihi dicendum sit, quos professores audierim, quam qualem studiorum rationem inierim. Quum enim litterarum quasi lumen ex professorum cathedra novo quodam splendare mihi affulgeret et novum quondam litterarum amorem in animo meo incenderet, jam eos solos mihi sequendos esse putari, eorumque sententias imbibens jam ex veritatis fonte mihi haurire videbar. Ita factum est, ut studium ad scholas, non scholas, ad studium accomodarem.
Über die Anlage der Studien wird nun zuerst zu sprechen sein. Auf der schule hing das Lernen ganz von Befehl und Autorität der Lehrer ab; aber damit ich wahrheitsgemäß gestehe: Auch zu jener Zeit [auf der Universität] zollte ich den meisten Tribut der Autorität der Professoren, so dass ich eher sagen müsste, welche Professoren ich gehört habe, als wie ich meine Studien eingerichtet habe. Das Licht der Wissenschaften, das mir mit einem neuen Glanz von den Kathedern der Professoren zuleuchtete, entzündete in meinem Geist eine neue Liebe zu den Wissenschaften, so dass ich glaubte, innen allein sollte ich folgen und - ihre Urteile einsaugend - 
Inter Theologos primum quidem Neander totum me habuit, deinde tamen magis magisque ad Schleiermacherum accessi, et ita ejus scholis tenebar, ut ne tum quidem, quum theologiae studium deposuissem, illius scholas deserere vellem.

Itaque non opus esse videtur, de theologiae studio verba facere. Nam ubi primum propriam quandam viam ingredi et intelligere coepi, scholas academicas, nisi parce decerptas, fructum ferre non posse: jam theologiae studio relicto ad philologiae studium descendere statueram.

Quod quidem consilium non subito exortum est, sed jamdudum praeparatum, denique prodiit. Num ille vitae rusticae amor, qui a (me) puero conceptus etiam in juventutem irrepserat, jam paullatim refrigescebat. Et animadvertenti mihi, eos theologos, qui a litteratorum hominum consuetudine segregati rure viverent, studia, quanto cumque amore ea amplexi essent, tamen plerumque negligere, metus invidit, ne idem mihi contingeret. Nam quid studia magis excitare et incendere potest, quam doctorum hominum consuetudo, disputationes, sermones? quid magis reprimere, quam litteraria solitudo? Et quis certo affirmare potuerit, fore ut, omni prope studiorum quasi materia subtracta, tamen eadem diligentia litteris studeat? Sed haec cogitatio, etsi interdum me angebat, tamen nondum plane me avocabat a Theologiae studio, spe adhuc relicta, fore ut aliquando urbano munere fungi possem. Sed ad hanc rationem mox aliud accessit. Quum enim viderem, longum intervallum interjectum esse inter Academicam vitam et illud tempus, quo munus illud inire possem, id in eo ponere meinte ich, schon aus der Quelle der Wahrheit zu schöpfen. So habe ich die Studien den Vorlesungen angepasst, nicht die Vorlesungen den Studien.

In der ersten Zeit nahm Neander mich ganz ein, dann aber ging ich allmählich immer mehr zu Schleiermacher über, dessen Vorlesungen mich so fesselten, dass ich sie auch dann noch nicht verlassen wollte, als ich das Studium der Theologie aufgegeben hatte.

So ist es auch nicht nötig, über das Studium der Theologie Worte zu verlieren. Denn sobald ich angefangen hatte, einen eigenen Weg zu beschreiten und zu begreifen, dass die akademischen Vorlesungen nur dann Frucht bringen können, wenn man sie sparsam aufnimmt, da hatte ich bereits das Studium der Theologie verlassen und beschlossen, zum Studium der Philologie herab zu steigen.

Dieser Entschluss ist übrigens nicht plötzlich entstanden, sondern, schon lange vorbereitet, ist er schließlich hervorgetreten. Denn die Liebe zum Landleben, die ich als Junge gefasst hatte und die noch ins Jünglingsalter hinein gekrochen war, erkaltete schon allmählich. Ferner bemerkte ich, dass die Theologen, die auf dem Lande lebten und des Umgangs mit Wissenschaftlern entbehrten, die Studien meistens vernachlässigten, mit wie großer Liebe sie sie vorher auch ergriffen hatten; daher beschlich mich die Furcht, es werde mir dasselbe zustoßen. Denn was kann die Studien mehr anregen und antreiben als der Umgang mit Gelehrten, Gespräche und Diskussionen mit innen; was kann sie mehr zurückdrängen als die Ferne von den Wissenschaften? Und wer könnte für sicher bestätigen, dass er - selbst wenn inm fast alle Hilfsmittel der Studien genommen wären - dennoch mit demselben Eifer den Wissenschaften folgte? Obgleich dieser Gedanke mich zuweilen ängstigte, riss er mich dennoch nicht ganz vom Studium der Theologie weg, da ja immer noch die Hoffnung blieb, es 
statui, ut animum ad obeundam illud munus pararem et adtingerem. Quod quidem duabus praecipue rebus me consecuturum esse sperabam, utrisque cum studio philologico conjunctis. Primum enim sperabam, fore, ut pueris docendis et informandis aptior evadam ad erudiendos et confirmandos juvenes virosque. Deinde confidebam, fore ut illo studio, quod totum fere litterarum coetum amplecteretur, et doctorum hominum communione, illum amorem incenderem, qui etiamsi remotus ab doctorum societate essem victurus, tamen nunquam exstingui posset. Ita primum quidem philologiae operam narans, id solum agebam, ut viam mihi sternerem; ad ea, quae majora duxi. Paulatim autem ipsum philologiae studium et docendi studium magis magisque adamare coepi.
Studia autem ita instituenda putavi, ut primum ad Graecam linguam, velut fundamentum quoddam linguae Latinae, et ad scriptores Graceos accederem, quippe qui et perse multo praeferendi essent Latinis, et ex quibus illi doctrinam suam et artem hausissent, intermixto tamen ad variandum studium uno et altero Romanorum scriptore. Deinde autem, hoc studio confirmato, ad mathematicam doctrinam me convertere statui, hanc a Graecae linguae studio nimis abhorrere ratus, quam ut eodem tempore utrique operam dare possem. werde geschehen, dass ich einmal in einer Stadt ein geistliches Amt bekleiden könnte. Zu diesem Gesichtspunkt trat bald noch ein zweiter hinzu. Ich habe mir nämlich sagen müssen, dass zwischen einem akademischen Leben und dem Zeitpunkte, zu dem ich ein solches Amt würde erhalten könne, gar lange Zeit verstreichen werde; da habe ich mir vorgenommen, diese Zeit zu benutzen, um meinen Geist auf ein solches Amt vorzubereiten. Das hoffte ich vor allem auf zwei Wegen zu erreichen, die beide mit dem Studium der Philologie verbunden sind. Erstens hoffte ich nämlich, wenn ich mich zunächst dem Unterrichte und der Erziehung von Knaben widmete, dadurch geeigneter zu werden, Jünglinge und Erwachsene zu erziehen und zu bestärken. Zweitens vertraute ich darauf, durch jenes Studium, das ja fast alle Gebiete der Wissenschaft umfasse [die Philologie], und durch die Gemeinschaft mit gelehrten Männern jene Liebe [zur Wissenschaft] zu entzünden, die wenn ich auch fern vom Umgang mit Gelehrten leben werde - dennoch niemals ausgelöscht werden könnte. So habe ich zuerst freilich Philologie nur deswegen betrieben, um mir den Weg zu ebnen zu dem, was ich für höher hielt. Allmählich aber begann ich das Studium der Philologie selbst und ebenso das Studium des Unterrichtens mehr und mehr zu lieben.

Ich beschloss, mich zuerst der griechischen Sprache zuzuwenden, gleichsam eine Art Grundlage der lateinischen, und ebenso den griechischen Schriftstellern, weil die schon an und für sich den lateinischen weit vorzuziehen und überdies die Quelle für deren Wissen und Können seien; dazwischen wollte ich der Abwechslung halber den einen oder den andern römischen Schriftsteller studieren. Danach aber, durch dieses Studium gefestigt, so beschloss ich, wollte ich mich der Mathematik zuwenden. Denn ich war der Meinung, dass die [Mathematik] zu weit von dem Studium der griechischen sprache entfernt sei, als dass ich sie beide gleichzeitig betreiben könnte. 
Quod ad Graecos scriptores attinet, diu multumque dubitavi, utrum ab Homero et dialecto Jonica initium facerem, et a veterrimo quoque scriptore gradum facerem ad eum, qui proximus esset aetate, an ab Atticis scriptoribus maximeque $a b$ historicis exorsus ad veteriores regrederer.
Was die griechischen Schriftsteller anbetrifft, habe ich lange und sehr gezweifelt, ob ich den Anfang von Homer und dem ionischen Dialekte nehmen und von den ältesten schriftstellern zu den zeitlich nächsten fortschreiten sollte oder ob ich mit den attischen Schriftstellern, besonders bei den Historikern beginnend, zu den älteren zurückgehen sollte.

Homero enim cognito, ex qua tanquam radice omnis recentiorum sermo effloruisset, jam me satis praeparatum et quum antiquis Graecorum moribus et institutis tum Graecae linguae quasi primordiis imbutam, ad poetas scenicos accedere posse putavi. Sed altera ex parte verebar, ne propria Homeri vis atque indoles me fugeret, si nondum alia lectione munitus ad eum legendem me conferrem; quum praefertim ${ }^{16}$ tanta ejus esset facilitas et venustas, ut nulla nobis legentibus difficultas objecta esse videretur.

Deinde reputavi, me Atticam dialectum jam magis cognovisse, quam Homericam, et facile fore, ut, quum ab illa ad hanc transirem, omnes dicendi formas figurasque commiscerem. Quod argumentum quum praevaleret, ea, quae jam aliqua ex parte mihi nota essent, firmiore notitia comprehendere statui, deinde autem ignota loca petere.

Ex Atticis igitur scriptoribus historicos delegi, quippe faciliores intellectu, et ad Graecam aetatem cognoscendam aptissimos. Cum historicis Graecae historiae et antiquitatum studium conjungendum censebam posthac ad tragicos descendere, et, cum his mythologiam et doctrinam metricam volui consociare. Quod ad grammaticae studium attinet, doctrina de verborum formis breviter percursa, statim ad Syntaxeos studium accessi, utpote quod quum ad cognoscendam veram linguae indolem vel plurimum faceret, tum vero aptissime cum prosaicis scriptoribus jungi posset, pleniorem vero formarum notitiam ad tragicos legendos distuli. Deinde Attica dialecto imbutus ad Homerum ejusque similem Herodotum regredi, in animo erat,
Den Ausschlag habe schließlich die Erwägung gegeben, daß er den attischen Dialekt doch schon besser kenne als den homerischen, und so habe er denn beschlossen, sich zunächst das schon Bekannte noch vertrauter zu machen und sich dann erst an Unbekanntes zu begeben. Unter den attischen Schriftstellern wählte er die Historiker, teils wegen ihrer leichteren verständlichkeit, teils weil sie besonders geeignet sind, in das Verständnis der ganzen Zeit einzuführen. Mit ihrem Studium wollte er das der griechischen Geschichte und der griechischen Altertümer verbinden. Nachher sollten die Tragiker an die Reihe kommen und zusammen mit diesen Mythologie und Metrik. In der Grammatik begab er sich, nachdem er die Formenlehre in aller Kürze durchgenommen hatte, gleich an das Studium der Syntax, weil das doch am besten in den Geist der sprache einführte und sich überdies mit dem Studium der Prosaschriftsteller sehr gut vereinigen ließ, die eingehendere Beschäftigung mit den Formen wollte er bis auf das Lesen der Tragiker verschieben. sobald er mit dem attischen Dialekte 
Platonem et Demosthenes ad illud tempus differendos esse ratus, quo ad mathematicum studium incumberem.

Quod consilium quomodo subinde mutaverim, infra dicetur.

In his legendis ita solebam versari, ut cujusque scriptoris locum aliquem majorem accurate explicarem, verborum structuram, constructionem, formam diligenter adnotarem, totamque illius scriptoris vim et ingenium, scribendi sentiendique rationem percipere studerem. Ita postquam viam mihi quasi ad eum intelligendum munivi, et certam quasi ejus imaginem mente concepi, jam celerius eum perlegebam, ita tamen, ut quum historiae nexum et fabulam si legi, ejus indolem et adornationem investigarem, tum vero ad Grammatica praecepta, quae modo percepissem, animum adverterem.

Ex Xenophonteis scriptis, quorum suavitas et naturalis sermonis facilitas egregie me delectabat, Cyri expeditionem, rerum Graecarum enarrationem, et Memorabilium atque Cyropaediae duos tresve libros legi. Deinde ad Thucydidem accessi, contrarium illum quidem Xenophonti, sed adstricta sua gravitate et perfecta historici virtute animum tenentem. Hunc totem perlegi exceptis ultimi libri aliquot capitibus, quae propter jejunitatem quandam et rerum gestarum magis enumerationem quam explicationem me tenere non possent.

Quod ad tragicos attinet, primum ad Sophoclem animum appuli, cujus jam notitiam aliquam feceram in schola Sedinensi. Ejusque Trachinias accuratius explicavi. Sed quum Sophoclis genügend vertraut sein würde, gedachte er zum Homer und dem mit diesem verwandten Herodot überzugehen. Plato und Demosthenes sollten für die Zeit aufgespart bleiben, wo er sich dem Studium der Mathematik widmen würde. (Engel 1911: 25-26)

Wie ich diesen Beschluss später geändert habe, wird unten berichtet.

Bei der Lektüre pflegte er so zu verfahren, daß er von jedem schriftsteller einen längeren Abschnitt genau erklärte, die Bildung und die Konstruktion der Wörter sorgfältig aufzeichnete und in die ganze Kraft und den Geist, in die Schreib- und Denkweise des verfassers einzudringen versuchte. Nachdem er sich so gewissermaßen den weg zum verständnisse des Autors gebahnt hatte und bereits ein gewisses Bild von diesem in seinen Geist aufgenommen hatte, las er ihn schneller durch, jedoch so, daß er, wenn er den geschichtlichen Zusammenhang und die Erzählung verstanden hatte, auch den dem Verfasser eigentümlichen Stil erforschte und dann auf die eben gelernten grammatischen Regeln acht gab.

Unter den Schriften Xenophons, deren leichte und natürliche schreibweise ihm viel Freude bereitete, las er die Anabasis, die Hellenika, die Memorabilien und zwei oder drei Bücher der Kyropädie. Dann begab er sich an den Thukydides, der zwar in scharfem Gegensatze zu Xenophon steht, der aber durch seinen gemessenen Ernst und durch seine hohe Vollkommenheit als Geschichtsschreiber außerordentlich anzieht. Diesen las er ganz, mit Ausnahme einiger Kapitel des letzten Buches, die ihn nicht fesseln konnten, weil sie etwas nüchtern sind und die Ereignisse eigentlich bloß aufzählen statt sie zu entwickeln.

Unter den Tragikern begann er mit sophokles, mit dem er schon vom Gymnasium her etwas bekannt war, und zwar arbeitete er die Trachinierinnen genau durch. Als er jedoch die 
lectionem jam prope absolvissem, subito studiorum ratio commutata est.

Quum enim assiduo labore animum nimis adstrinxissem, corporisque vires contrivissem: in morbum quendam incidi non gravem illum quidem nec periculosum, sed tamen eum, qui me ab inita studiorum ratione et toto vitae consilio avocaret. Nam tum primum, me naturae repugnasse intellexi, et dum celeritatem quandam discendi et agendi, abhorrentem illam a mea natura, affectavissem, corporis valetudinem me labefactasse. Nec tamen adduci poteram, ut, quod animo excolendo corpori videbar damnum afferre, ad corpus curandum animum languescere finerem $^{17}$. Sed illud corporis et animi quasi dissidium non in rerum natura positum esse cognovi, sed ex falsa, quam ingressus esses, via oriri; quinetiam utrumque ita se invicem tueri, ut animum si ea ratione, quam natura praescripsisset, ex colendum curaremus, etiam corpori nihil salubrius esse posset; sin autem animum supra modum intenderemus, vel nimis remitteremus, unde et corpori et animo incommodum nasci.

Qua de causa studia mea meae naturae regula metiri statui, et moderato quodam sed eo non minus diligenti studio viam meam persequi; animum non obruere rerum scientia, sed exstruere et locupletare. Utrumque autem quomodo secerni posset, non dubitavi. Nam quum omnia studia ex amore quodam litterarum et discendi cupiditate oriri deberent, nullum his studiis modum esse praescriptum putavi, nisi quem, ipsa illa quae nos impelleret discendi cupiditas definiret; quidquid autem
Lektüre des Sophokles schon beinahe vollendet hatte, sah er sich plötzlich genötigt, die ganze Art und Weise seiner Studien zu ändern. (Engel 1911: 26-27)

Da ich nämlich durch die unausgesetzte Arbeit meinen Geist allzu sehr angestrengt und auch die Körperkräfte aufgerieben hatte, verfiel ich in eine Krankheit. Obgleich diese weder schwer noch gefährlich war, so doch von der Art, dass sie mich von der bisherigen Anlage der Studien und meinem ganzen Lebensplan abzog. Denn erst jetzt sah ich ein, dass ich gegen die Natur angekämpft hatte, und dass ich meine leibliche Gesundheit erschüttert hatte, als ich die Schnelligkeit des Lernens und des Handelns angestrebt hatte, die meiner Natur zuwiderlief. Doch konnte ich mich nicht dahin bringen, dass ich - da ich doch dem Körper Schaden zu bringen schien, indem ich den Geist ausbildete - den Geist darauf beschränkte zu erschlaffen, um den Körper wiederherzustellen. Dagegen erkannte ich, dass dieser an Widerstreit grenzende Gegensatz zwischen Körper und Geist nicht in der Natur der Dinge begründet, sondern durch die falsche Bahn, die du [=ich] eingeschlagen hattest, hervorgerufen sei. Vielmehr beschützen sie sich gegenseitig derart, dass, wenn wir den Geist auf eine Weise, die die Natur vorgeschrieben hätte, auszubilden uns bemühten, auch dem Körper nichts heilsamer sein könnte. Wenn wir dagegen den Geist zu sehr anstrengten oder zu sehr vernachlässigten, entstünde daraus sowohl dem Körper als dem Geiste Schaden.

Aus diesem Grunde beschloss ich, meine Studien an der Regel meiner Natur zu messen und in gemäßigtem aber nicht minder sorgfältigem Bemühen meinen Weg zu verfolgen; den Geist also nicht mit Wissensstoff zu überhäufen, sondern inn aufzubauen und zu bereichern. [Dass ich wüsste,] wie aber beides unterschieden werden könnte, daran zweifelte ich nicht. Da nun alle Studien aus der Liebe zu den Wissenschaften und aus der Begierde zu lernen hervorgehen sollten, hielt ich dafür, dass innen 
animum extra hunc modum impelleret, id non ab illo discendi studio, sed ab alieno quodam consilio proficisci. Itaque studium quodque interrumpi debere, priusquam fastidium quoddam oriretur, totamque rationem in eo versari, ut naturam solam sequens, eam indagares, omnia quae aliena esse viderantur vel incitamenta vel impedimenta semoveras, et ita ad id, quod tibi proposuisses, contenderes. Hoc autem ut fieri posset, non solum id agendum duxi, ut labor et relaxatio invicem se exciperent, sed etiam ut studia ipsa quam maxime variarentur. Nec tamen studia ita varianda esse, ut res plane diversas et inter se discrepantes consociarem, sed ut quantum fieri posset; omnia, quae agerem, societatis quodam vinculo continerentur, studii autem varietate disjungerentur. Et quae major varietas inveniri potest, quam in his humanioribus litteris? Quid enim dissimilius est, quam in Homero legendo ejus venustatem et leporem mente concipere, et ejus dialectum dicendique rationem indagare? quid disjunctius, quam tragicorum vim et gravitatem percipere et, metris quibus usi essent, exscrutari?

Itaque primum quidem, quod adhuc infirma erat valetudo, ab Sophocle ad Homerum, et Terentium declinari, eosque ad reficiendum magis animum, quam locupletandum rerum cognitione legi. Eodem tempore Boeckhii historiam litterariam Graecorum audivi, summamque inde cepi voluptatem. Quas scholas ut magis in meum usum verterem, majoremque inde ferrem fructum, bibliotheca diligenter uti statui, ut imaginem vel scriptoris vel totius daher kein andres Maß vorgeschrieben sei, als es diese Begierde zum Lernen, die uns antriebe, schon selbst festlege. Was aber den Geist außerhalb dieses Maßes antreibe, das gehe nicht aus jenem Bemühen um Kenntnisgewinn sondern aus einem anderen Ratschlag hervor. Deshalb müsse jedes Studium abgebrochen werden, noch bevor sich eine Spur von überdruss zeige. Und alles komme darauf an, dass du einzig und allein der Natur folgend diese erforschest und alles Fremde, seien es Anreize, seien es Hindernisse, aus dem Wege räumst. So würdest du dich eilig nach dem, was du dir vorgenommen hättest, begeben. Zur Erreichung dieses Ziels meinte ich, sei es aber nicht nur nötig, dass Arbeit und Erholung sich gegenseitig ablösten, sondern dass auch die Studien in sich soviel wie möglich abgewandelt würden. Doch seien die Studien nicht so abzuwandeln, dass ich ganz verschiedene und unter sich widersprüchliche Gegenstände verbände. Vielmehr sollte alles, was ich betriebe, soweit als möglich durch das Band einer Gemeinsamkeit zusammengehalten werden, durch Abwechslung im Studium aber getrennt werden. Und welche größere Mannigfaltigkeit lässt sich finden als die in diesen humanistischen Wissenschaften? Was nämlich ist verschiedener, als beim Lesen des Homer dessen Schönheit und Anmut mit dem Geist zu erfassen oder seinen Dialekt und den Stil zu erforschen? Was liegt einander ferner, als die Kraft und die Würde der tragischen Dichter zu erfassen und zu untersuchen, welcher versmaße sie sich bedient haben?

Deshalb habe ich mich zuerst freilich, weil ich mich gesundheitlich noch schwach fühlte, von Sophokles ab und Homer und Terenz zugewandt; diese las ich mehr um meinen Geist wieder zu stärken als um inn mit Kenntnissen zu bereichern. Um dieselbe Zeit hörte ich bei Boeckh Literaturgeschichte der Griechen, die mir höchste Freude machte. Um diese Vorlesungen mehr zu meinem Nutzen zu verwerten und größeren Gewinn daraus zu ziehen, beschloss 
litterarum generis, quam ille adumbraret, ipse inspiciendis et carptim legendis illis scriptoribus in animo meo informarem.

Quod tamen consilium variis rebus, quas afferre non interest, interruptum est et renovatum. His studiis postremus vitae Academicae annus consumptus est.

Domum deinde quum revertissem unum et viginti annos natus: firmata jam valetudine, studia severiora renovavi, et ut antea constitueram, in matheseos studium antea jam inchoatum, incubui, humanioribus litteris si minus neglectis, tamen posthabitis, ita ut magis eas ad variandum studium, ad firmandam et servandam earum cognitionem, ad supplendum denique, quod reliquissem, adhibendos esse censerem. Qua de re hoc tantum dicam, me Livii Caesarisque aliquot libros cum Romanae historiae studio, Homerum, Horatii carmina et Aeneidos aliquot libros cum mythologiae studio junxisse.

Cum mathematicis doctrinis Physicen et historiam naturalem conjunxi. Atque in mathematico studio ita solebam versari, ut ea quae ad Geometriam magis pertinerent cum Arithmeticis disciplinis consociarem. Ita enim me studiorum rationem maxime variaturum esse sperabam, quum Geometria res demonstratas vel demonstrandas quasi ante oculos poneret; Arithmeticae autem disciplinae mente et cogitatione percipiendae essent. Qua de re Geometriae et Arithmeticae eodem tempore operam navavi, alteri, Legendri Elementa, alteri Vegae ich, sorgfältig die Bibliothek zu benutzen. Das Bild, das er [Boeckh] von einem einzelnen Schriftsteller oder von einer ganzen Literaturgattung umriss, wollte ich durch eigenes Nachschlagen und durch Lesen einzelner Abschnitte jener Schriftsteller in meinem Geiste mir vorstellen.

Dennoch ist dieser Plan durch verschiedene Umstände, die anzuführen nicht wichtig sind, unterbrochen und erneuert worden. Mit diesen Studien ist das letzte Jahr des akademischen Lebens beendet worden.

Als ich darauf nach Hause zurückgekehrt war, war ich 21 Jahre alt: Als meine Gesundheit schon wieder fest war, nahm ich wieder ernstere Studien auf, und wie ich früher beschlossen hatte, verlegte ich mich auf das Studium der Mathematik, das ich schon früher begonnen hatte. Wenn ich auch die humanistischen Wissenschaften wenig vernachlässigt habe, so setzte ich sie dennoch hintan, so wie ich urteilte, dass sie mehr hinzugenommen werden müssten, um das Studium zu variieren, um die Kenntnis dieser Bereiche zu befestigen und zu bewahren, schließlich um zu ergänzen, was ich vernachlässigt habe. Darüber will ich nur dieses sagen, dass ich einige Bücher von Livius und Caesar mit dem Studium der römischen Geschichte, Homer, die Gedichte von Horaz und einige Bücher der Aeneis mit dem Studium der Mythologie verbunden habe.

Mit den Lehren der Mathematik habe ich die Physik und die Naturgeschichte verbunden. Und das mathematische Studium pflegte ich so zu betreiben, dass ich das, was mehr zur Geometrie gehörte, mit den arithmetischen Disziplinen verband. So hoffte ich nämlich, dass ich die Ordnung der Studien möglichst abwechselnd gestalten würde, weil die Geometrie das, was sie bewiesen hat oder was bewiesen werden soll, gleichsam vor die Augen stellt; die arithmetischen Disziplinen müssen dagegen mit dem Geist und mit dem Denken erfasst werden. Aus diesem 
lectiones secutus. Deinde ad combinandi doctrinam accessi, ut quae viam mihi sterneret ad altiores Mathematicas disciplinas, patris usus schedis et commentationibus. Posthac Trigonometriam et planam et sphaericam aggressus sum, item patris schedis usus. Ad sectiones deinde conicas accessi, Schneideri librum de hac re conscriptum secutum, eas quum geometriae et Arithmeticae notitiam firmare tum ad calculum differentialem et integralem viam facere ratus. Huic studio adnexi serierum finitarum et infinitarum functionumque doctrinam, aequationes tertii quartique gradus, et calculi differentialis prima rudimenta. His studiis absolutis, commentationem quandam minorem conscripsi de geometrica Analysi et de adhibenda Arithmetica et Algebra ad Geometriam ut utriusque notitiam firmarem, et id, quod luce carere videretur, illustrarem. Ita praeparatus ad calculum differentialem accessi eumque ex Meyeri libro (vollständiger Lehrbegriff der höheren Analysis) percepi.
Physicen secundum Fischeri librum percurri, idque ita ut opticen cum sectionibus conicis conjungerem.

Quod denique ad historiam naturalem attinet Goldfussii librum de Zoologia conscriptum perlegi, mineralogiae et botanicae prima elementa percepi, uberiorem harum doctrinarum cognitionem et Astronomiae et Chemiae Studium in aliud tempus differens.
Grunde betrieb ich die Arbeit an der Geometrie und der Arithmetik zur gleichen Zeit eifrig, indem ich in der einen den Elementen Legendres und in der anderen den Vorlesungen Vegas folgte. Dann befasste ich mich mit der Kombinationslehre, damit diese mir den Weg zu den höheren mathematischen Disziplinen bahnte, wobei ich die Hefte und Abhandlungen des Vaters benutzte. Danach bin ich an die ebene und sphärische Trigonometrie herangegangen, indem ich ebenfalls die Hefte des Vaters benutzte. Dann habe ich mich an die Kegelschnitte gemacht, indem ich dem Buch Schneiders, das er darüber geschrieben hat, gefolgt bin, an diese in der Meinung, sowohl die Kenntnis der Geometrie und Arithmetik zu festigen als auch besonders um einen Zugang zur Differentialund Integralrechnung zu finden. An dieses Studium knüpfte ich die Lehre von den endlichen und unendlichen Reihen und Funktionen, die Gleichungen dritten und vierten Grades und die ersten Anfänge der Differentialrechnung an. Nachdem ich diese Studien absolviert hatte, schrieb ich eine Art kleiner Abhandlung über die geometrische Analysis und über die Anwendung der Arithmetik und Algebra auf die Geometrie, damit ich die Kenntnis von beiden befestigte und das, was des Lichtes zu entbehren schien, erleuchtete. So vorbereitet begab ich mich an die Differentialrechnung und lernte sie nach dem Buch von Meyer (Vollständiger Lehrbegriff der höheren Analysis).

Die Physik ging ich nach dem Buch von Fischer durch, und dies so, dass ich die Optik mit den Kegelschnitten verband.

Was endlich die Naturgeschichte anbelangt las ich das Buch durch, das Goldfuß über die Zoologie geschrieben hat, lernte die ersten Elemente der Mineralogie und Botanik, indem ich eine ausführlichere Kenntnis dieser Lehren und das Studium der Astronomie und der Chemie auf eine andere Zeit verschob. 
Specimen tum propter rerumubertatem tum propter stilii venustatem et elegantiam laude dignum.

Köpke ${ }^{18}$

\title{
Die Pastoren-Prüfung
}

\author{
Abschrift \\ Lebens-Lauf (Stettin, 23. März 1833) ${ }^{19}$
}

Jedem, der sich die Aufgabe gestellt hat, sein eignes Leben, nicht bloss den äusseren Umständen, sondern auch dem innern Entwicklungsgange nach, darzustellen, ist dies wohl besonders dadurch schwierig geworden, dass er einestheils nicht sicher ist, ob er sich auch mit dem rechten Massstabe messe, und dass er anderntheils gestehen muss, sich selbst noch nicht recht erkannt zu haben; überdies liegen ja gerade, die Momente, welche gleichsam die Grundlage unserer Entwickelung bildeten, in der Zeit, wo mir, selbst noch nicht zum Bewusstsein gereift, uns selbst auch nicht beobachten und durchschauen konnten. Besondere Schwierigkeiten treten aber noch in diesem bestimmten Falle auf; denn soll man eine solche Lebensbeschreibung nicht bloss für sich, sondern auch für Andere entwerfen, so ist es nicht möglich, alle Einfluss übenden Umstände aufzustellen, die man kennt; indem nämlich viele davon doch dem Andern unverständlich sein würden; und schwierig ist es, sich rein und offen darzustellen, indem man doch oft unbewusst Einzelnes ohne Noth zu verhüllen sucht.

Mein äusseres Leben ist überaus gleichförmig. In Stettin wurde ich 1809 geboren und erzogen; zuerst besuchte ich eine Privatschule, von Quinta an das Gymnasium; den Religions-Unterricht genoss ich bei dem Prediger Zybell. Darauf bezog ich $1827 \mathrm{zu}$ Michaelis die Universität, studierte dort besonders Theologie und zuletzt auch Philologie, und kehrte nach Vollendung des Akademischen Trienniums nach meiner Vaterstadt zurück, wo ich nach halbjähriger Vorbereitung als Hülfslehrer am Gymnasium angestellt wurde. Was meine religiöse und theologische Entwickelung anbetrifft, so kann ich in ihr besonders 3 Zeiträume unterscheiden, zwischen denen freilich keine scharfe Abgränzung statt finden kann.

Erstens Die Zeit des religiösen (sittlichen und intellektuellen) Schlummers; etwa bis zur Einsegnung 1823.

Zweitens Die Zeit der streng orthodoxen Ansicht vom Christenthum, wie ich sie von meinem hochverehrten Religions-Lehrer, dem Prediger Zybell, aufgefasst hatte. 
Drittens Die allmälige Befestigung der Schleiermacherschen Ansicht. Der Uebergang zwischen den beiden letzten Zeitabschnitten konnte natürlich erst allmälig zu Stande kommen; doch, um eine etwas bestimmtere Gränze zu ziehen, so gewann Schleiermachers Ansicht erst im letzten Jahre der Universitäts-Zeit rechten Einfluss auf mein ganzes Leben d.h. auf meine religiöse, sittliche und intellektuelle Entwickelung, so dass also das Jahr 1829 als Gränze beider Zeiträume gelten kann.

Erster Abschnitt Die Zeit des religiösen Schlummers bis 1823 Wenn ich diese Zeit eine Zeit des Schlummers nenne, so will ich dies keinesweges in dem Sinne behaupten, in welchem wohl jeder seine Kindheit und sein Knabenalter einen Schlummer nennen könnte, in sofern das höhere Bewusstsein noch im Keime ruht, und erst allmälig die geistigen Kräfte aus dem sinnlichen Bewusstsein heraus sich entwickeln; sondern ich meine dies im vollen Sinne des Wortes; - so dass ich darin gerade mich von fast allen meinen Alters-Genossen unterschied. Nur folgendes diene zur näheren Charakteristik dieses Zeitraums: Einer geistigen Anstrengung war ich nicht fähig; daher geschah' es, dass ich im Auffassen so wohl mit dem Verstande als mit dem Gedächtnisse hinter meinen Mitschülern zurückblieb; - und, was am meisten jene Zeit einem Schlummer ähnlich machte, waren die Träumereien, welche vermöge meiner geistigen Trägheit Raum gewannen, und durch die Eigenliebe genährt, einen grossen Theil meines damaligen Lebens füllten; das höchste Glück schien mir das zu sein, wenn ich frei, von allen Geschäften, von allen geehrt und geliebt, ein sorgenfreies angenehmes Leben führen könnte; und da nun mein Leben weit von einer solchen Lage entfernt war, so träumte ich mir eine solche vor; dünkte mich selbst in diesen Träumereien geliebt und geehrt, spielte in ihnen immer die erste Rolle, und nährte so ohne dass ich es wusste, meine Eitelkeit und Eigenliebe.

Wie dies nun die geistigen Kräfte unterdrücken, mich für Eindrücke aller Art immer unempfänglicher machen musste, ist leicht zu denken. Daher kam kam [sic!] es auch, dass mein Gedächtnis nicht nur höchst langsam, sondern auch sehr untreu war; indem das, was ich durch das Gedächtniss wirklich gefasst hatte, durch die formlosen Träumereien wieder verwischt wurde; daher kam es, dass ich in dem gemeinsamen Leben mit den Knaben immer eine untergeordnete Rolle spielte; selbst in den Spielen nur immer ihren Plänen und Anschlägen folgte, mich immer leiten liess, ohne irgend selbst zu leiten; daher kam es endlich, dass selbst religiöse Eindrücke bald wieder durch jene Träumereien ausgelöscht wurden. So zerstörten also jene Träumereien die Keime des Guten, hemmten jede 
frische Thätigkeit und Entwickelung und machten mich sogar für's äussere Leben ungeschickt. Dass ich nun damals schon den Entschluss gefasst hatte (wenn ich es so nennen darf), einst Prediger zu werden, das hing wieder ganz eng zusammen mit jenem Schlummerleben. Die Ferien brachte ich nämlich meistentheils bei meinen Verwandten auf dem Lande zu, welche fast alle Prediger waren; und da mir diese sorgenlose Zeit immer sehr angenehm verging; so bildete ich mir ein, dass namentlich der Landprediger ein solches Leben führte, wie ich es mir als das höchste Glück vorgestellt hatte. Entfernt von dem Geräusche und Getreibe der Stadt, so dachte ich, lebte er in seiner Gemeinde geehrt und geliebt ein sorgenfreies, angenehmes Leben; - freilich dachte ich mir zu andern Zeiten auch oft den Beruf selbst und die Wirksamkeit eines Predigers als etwas Schönes des Anstrebens Würdiges.

Zweiter Abschnitt. Streng orthodoxe Ansicht vom Christenthum.

Wenn ich hier zuerst die Impulse angeben soll, welche mich aus jenem Schlummer weckten, oder vielmehr den Anfang des Erwachens bildeten, so waren sie in der That von der manigfachsten Art: Die Neckereien der Mitschüler, die Ermahnungen der Ältern und vor allem der religiöse Einfluss, welchen der Prediger Zybell in seinem Konfirmationsunterrichte, den ich drei Jahre lang genoss, auf mich übte; alles dies wirkte zusammen. Die religiösen Eindrücke gaben den ersten Anstoss; erst durch das allmälige Erwachen des religiösen Sinnes konnten die Neckereien, die bisher nur meine Eitelkeit gereizt hatten, so wirken, dass sie mich zur Selbsterkenntniss führten; erst dadurch wurde das Gemüth für die väterlichen Ermahnungen empfänglich gemacht. Wenn gleich nun schon vor jener Zeit, die ich die Zeit des geistigen Erwachens nennen möchte, einzelne gleichsam wache Momente vorhergingen; so fing ich doch erst damals und fast plötzlich an mich zu ermannen; es ward mir klar, wie ich bisher nur geträumt hätte; es ging mir gleichsam plötzlich ein Licht auf über mein vergangenes Schlummer-Leben; und ich beschloss nun alle meine geistigen Kräfte anzuregen und zu wecken. Ich war damals in Tertia; und hatte gerade ein Gedicht zu lernen, wozu ich mir eine Stelle aus Klopstocks Messias gewählt hatte; den frischen Entschluss meine Kräfte zu wecken, wandte ich zuerst hierauf an; ich nahm mir vor, alle meine Kraft anzustrengen, um den Sinn dessen, was ich lernen wollte, mir recht lebhaft zu vergegenwärtigen, und es gelang über alles Erwarten. So geringfügig dies scheinen mag, so wichtig war es für mich; es war das Gelingen des ersten Vorsatzes. Nun erst sah ich ein, dass nur meine Schuld es gewesen sei, wenn ich früher nichts hatte fassen können, nun erst ward mir ganz klar, dass ich erwachen müsste und könnte. Voll 
Vertrauen und mit der Seligkeit erfüllt, die das erste Gelingen eines ganz frischen Vorsatzes mit sich führt, beschloss ich nun mein ganzes Leben aufzuwecken. In der That wurden meine deutschen Aufsätze, die bis dahin sich nur gerechten Tadel zugezogen, seitdem meist von den Lehrern gelobt; als ob ich damals erst zu denken angefangen hätte. Auch in dem äusseren Leben wurde ich seitdem lebhafter. Durch diesen günstigen Erfolg bestärkt, suchte ich nun meine Prinzipien immer fester auszubilden und konsequenter durchzuführen. - Nun erst konnte auch eine religiöse Ueberzeugung in mir entstehen; da ich erst jetzt durch die Erfahrung den Einfluss der Religion empfunden hatte; ich hielt fest an der religiösen Ansicht meines hochverehrten Religion-Lehrers, welcher ganz den Reformatoren und namentlich Luthern anhing; jeder Zweifel dagegen erschien mir tadelns werth, und wo sich daher ein solcher regte, suchte ich ihn aufs Ernstlichste zu unterdrücken. So erinnere ich mich namentlich noch, dass mir kurz vor der Einsegnung die Art, wie uns der Prediger die Nothwendigkeit des Kreuzestodes Jesu darzustellen suchte, durchaus nicht einleuchten wollte; und wie mich das um so mehr beunruhigte, als ich glaubte, das Glaubensbekenntniss mit der vollsten Ueberzeugung von der Nothwendigkeit jenes Todes ablegen zu müssen; Ich wandte daher alles an, um jeden Zweifel zu beschwichtigen, und so gelang es mir wirklich, sie wenigstens zu unterdrücken. - Ich habe schon erwähnt, wie nach und nach jene Principien sich bestimmter gestalteten; und so will ich sie denn in der Art aufstellen, wie sie sich gegen das Ende meines Schullebens ausgeprägt hatten. Ich meinte nämlich, das geistige Talent beruhe nur auf der Kraft, mit der wir den Geist anzuregen vermögen; ein Talent zeige sich nur in dem Masse, als man im Stande sei den Geist in Bewegung zu setzen; - nicht das Schicksal gestalte den Menschen, sondern der Mensch sich selbst, und dadurch auch die Art, wie das Schicksal auf ihn wirkt; allen sei Ein Ziel vorgesteckt: die Vollkommenheit (Gottähnlichkeit), welche für alle Menschen dieselbe sei; mein phlegmatisches Temperament müsse von Grund aus vertilgt werden, denn ein solches schien mir mit der Vollkommenheit unverträglich. - Ich darf wohl nicht ${ }^{20}$ hinzufügen, dass diese Grundsätze keineswegs konsequent durchgeführt wurden, was um so weniger möglich war, da sie in ihrer Einseitigkeit durchgeführt, nur das individuelle Leben zerstört hätten. So irrig sie indessen zum Theil sein mochten, so trugen sie doch unendlich viel bei zur Aufweckung meines Innern; und vor dem Hochmuth und Selbstvertrauen, wozu sie leicht hätten führen können, bewahrte mich doch immer das Gefühl meiner Schwäche, was mir aus dem Zurückbleiben der Ausführung hinter dem Vorsatze 
hervorging. So kam ich auf die Universität, wo mich Neander vor allen anzog, der die Ansichten, wie ich sie bisher noch zum Theil als einen todten Schatz in mir getragen, belebte, vergeistigte und sie so mehr zu meinem Eigenthume machte; der die bisher nur niedergedrückten Zweifel auflöste oder beschwichtigte. - In der grösseren Fröhlichkeit und Unbesorgtheit welche die erste Zeit des Universitäts-Lebens anzuregen pflegt, fingen denn die früheren Grundsätze an einzuschlummern, oder hallten wenigstens nur noch nach; dagegen fing der folgende Zeitraum an sich vorzubereiten.

Dritter Abschnitt Die Zeit, in welcher die Schleiermachersche Ansicht vorherrschte.

Ehe ich zur Schilderung dieses Zeit-Abschnittes übergehe, muss ich mich gegen einen Missverständniss bewahren, welches leicht aus den Ueberschriften, durch die ich einen jeden Zeitraum zu charakterisiren suche, hervorgehen könnte. - Nämlich schon indem ich die theologische Ansicht im vorigen Zeitraume als ein Festhalten an der streng orthodoxen Ansicht darstellte, wollte ich keinesweges behaupten, dass diese Ansicht auch vollständig mein Eigenthum gewesen sei; es zeigte sich vielmehr sogar ein recht antilutherisches Element darin, dass ich oft nur die äusseren Werke umzuwandeln bestrebt war; also auf diese einen besonderen Werth legte; wohingegen der Blick noch nicht so geschärft war, um bis ins Innere selbst zu blicken und das Innere umzuwandeln.

Eben so wenig will ich hier behaupten, dass ich die Schleiermacherschen Ansichten ganz zu meinem Eigenthum gemacht hätte (da ich ja vieles davon nicht verstand); indessen gewann er doch einen so mächtigen Einfluss auf meine Entwickelung, ich habe ihm in geistiger Hinsicht so unendlich viel zu danken, dass ich nur ihn an die Spitze dieses Abschnittes stellen kann. - Schon im zweiten Semester hatte ich Kollegia bei Schleiermacher gehört, die ich aber nicht verstand; dagegen fingen seine Predigten an, Einfluss auf mich zu gewinnen. Doch erst im letzten Jahre zog mich Schleiermacher ganz an, und, obwohl ich damals schon mich mehr mit der Philologie beschäftigte, so erkannte ich doch nun erst, wie man von Schleiermacher für jede Wissenschaft lernen kann, weil er weniger Positives giebt, als er geschickt macht, eine jede Untersuchung von der rechten Seite anzugreifen und seIbständig fortzuführen und so in den Stand setzt, das Positive selbst zu finden. - Zugleich hatten auch seine Ideen selbst mich angeregt, seine Predigten mein Gemüth erweckt; und dies konnte nicht ohne Einfluss auf meine Grundsätze und meine ganze Denkweise bleiben. Dazu kam noch eine Krankheit, die mich ernster stimmte, und mich auf mich selbst zurückwies; und so kam ich denn mit der Zeit zu der Erkenntniss, 
dass meine bisherigen Grundsätze falsch und einseitig gewesen seien. - Ich sah ein, dass das Ankämpfen gegen das Temperament ein durchaus vergebliches, ja verderbliches Abmühen gewesen sei; ein vergebliches, weil es doch nie gelingen könne, das Temperament $\mathrm{zu}$ vernichten oder in das entgegengesetzte $\mathrm{zu}$ verwandeln; ein verderbliches, weil damit immer nothwendig ein Zerstören des Körpers, ein Aufheben der Geisteseigenthümlichkeit, also überhaupt eine Zerstörung des individuellen Lebens verbunden sei. Es sei mir vergönnt, eine Stelle aus meinem Tagebuche, was ich etwa in jener Zeit zu führen anfing, hierher zu setzen.; „So muss der Phlegmatische nicht dahin streben, den Schlendrian seiner Gedanken zu einem kühnen Fluge antreiben zu wollen; denn die Flügel, mit denen er zur Sonne sich aufzuschwingen strebt, sind nicht ihm eigenthümlich; und er wird daher bald wie Ikarus auf die Erde zurückstürzen. Er muss vielmehr seinem Gedankengange Klarheit zu geben suchen und in der Klarheit Tiefe; wohingegen der, dessen Gedanken wie im Strome gleichsam fortgerissen werden, auch viel Schlamm und Koth mit aufwühlt." Dem gemäss gestaltete sich denn auch die Idee von der Anstrengung um; und diese sollte sich jetzt nur darauf hinwenden, alles, was die Sinnlichkeit dem Geiste hemmend entgegenstellte wegzuräumen; und dies Streben richtete ich, so viel ich konnte, auf alle Lebensgebiete (nicht bloss auf das der Wissenschaft). Dies mochte der Anfang der neuen sittlichen Anregung sein, aber auch nur der Anfang; ich erkannte mich selbst noch nicht; denn indem ich bemerkte, dass oft die Sinnlichkeit und Eitelkeit zu meinen Handlungen mich bewegte oder bewegen half, und indem ich doch glaubte dass ich mitunter auch zu rein sittlichen Handlungen und Gedanken fähig sei, so meinte ich, in mir trete sich das Moralische und Unmoralische schroff gegenüber; bald siege das eine, bald siege das andere; bald sei meine Gesinnung rein, bald aufs höchste verderbt; und indem ich so mein Inneres in den stärksten Schwingungen zwischen dem Guten und Bösen hin und her schwankend glaubte, so fehlte mir der rechte Massstab meiner selbst. Erst späterhin ward mir klar, dass, wenn ich einmal die Sinnlichkeit und Eitelkeit in dem einen Lebensgebiete erkannt hätte, ich sie auch in jedem andern Lebensgebiete aufsuchen, und auch dort ihre Macht enthüllen und zerstören müsste. Denn da der Geist doch nur Einer sei, und nicht heute dieser, und morgen wieder ein ganz anderer; so müsse auch jeder Glaube an eine Fähigkeit $\mathrm{zu}$ rein sittlichen Handlungen, wenn man doch zu andern Zeiten wieder die Eitelkeit in ihrer ganzen Macht herrschend finde, nur leere Selbsttäuschung sein. Ich suchte die Eitelkeit den Egoismus in jeder meiner Handlungen auf; und fand, dass er überall meine Handlungen ja meine 
Gedanken mit seinem Gift befleckte und durchdränge. Mein letztes Ruhekissen war mir hinweggezogen; ich sah die Einheit meines Geistes; aber eine Einheit, wie ich sie nicht geahnt noch gewünscht hatte. Unausgesetzt wollte ich nun kämpfen gegen die mächtigen Gegner in meinem Innern, die von jener Zeit der Träumereien her noch in mir herrschten; und die sich in der nachfolgenden Zeit des Erwachens doch geschickt in die geheimsten Schlupfwinkel des Herzens zurückgezogen hatten, um, wenn ich sorglos und unbewacht war, wieder hervorzubrechen. Aber auch damals war mein Streben nur negativ, ankämpfend. Und wie sich allmälig das Positive zu gestalten anfing; wie ich allmälig statt die Grundsätze, die ich aus mir selbst entwickelt hatte, an die Spitze meiner sittlichen und religiösen Bildung zustellen, zu der Ueberzeugung gelangte, dass die Ideen höher begabter und sittlich vollkommnerer Menschen, und namentlich die Worte und das Beispiel dessen, der das Bild der Gottheit in der Menschheit darstellte; und von dem zuletzt alles geistig und religiös' anregende als aus der ersten Quelle ausginge, nicht nur allseitigere Principien anregen, sondern auch eine Begeisterung eine höhere Kraft und ein neues Leben uns mittheilen; wie sich das Alles in mir entwickelte und fester gestaltete, das gehört der letzteren Zeit meines bisherigen Lebens an; über die ich nicht urtheilen will noch kann; weil einestheils mein Urtheil, da ich selbst noch in dieser Zeit 1ebe, befangen und einseitig sein muss, und weil anderntheils die Darstellung meiner theologischen Ansichten in meinen übrigen Arbeiten theilweise niedergelegt ist. Eine Stelle aus meinem Tagebuche, welche gerade am Ende jener negativen Periode geschrieben wurde, möge hier noch ihren Platz finden, weil sie den ganzen Entwickelungsgang bis zu jenem Punkte zusammenfasst; "Auch ich führte einst ein Leben, was auf den Genuss ausging, und träumend malte ich mir aus den aufbewahrten Strahlen der Vergangenheit ein genussreiches Bild der Zukunft vor. Darüber vergass ich Gegenwart und Vergangenheit, und auch die Zukunft trieb mir nur gaukelnde Bilder vorüber (erster Abschnitt). Darunter drohte mein geistiges Leben unterzugehen. - Ich schlief. - Da ertönte vielfach die Stimme des Bessern in mir; ich erwachte; ich fand meine Freude an der Thätigkeit; thätig wollte ich umbilden das Leben; aber ich erkannte nicht das innere Leben; nur sein Spiegelbild erblickte ich im äusseren Leben; das wollte ich umgestalten und glaubte mein Inneres selbst umzuwandeln. Das Leben theilte ich ab, prüfte die Werke; manches gelang; vieles blieb liegen (zweiter Abschnitt). Noch einmal erwachte ich, blickte rückwärts, den Geist wollt' ich bilden, aber ich erkannte ihn nicht und bald stand ich wieder unter der drückenden Herrschaft das äusseren Vorsatzes." 


\section{Anmerkungen}

1 Als Teil der neuhumanistischen Bildungsreformen in Preußen waren 1810 wissenschaftliche Deputationen und ab 1817 wissenschaftliche Prüfungskommissionen eingeführt worden, die künftige Lehrer in einem Staatsexamen prüften. Sie waren im Wesentlichen mit Universitätsprofessoren besetzt, die in den Hauptfächern des Gymnasiums prüften: siehe Schubring 1991: $113 \mathrm{f}$.

2 Auskunft des Archiwum Panstwowe w Szczecinie vom 23. Juli 1985.

3 Ich danke Frau Jolanta Liskowacka, Książnica Pomorska Szczecin, für diese Klärung der Identität des Transskriptors.

4. Szczecin, Książnica Pomorska, Handschriftenabteilung, Signatur Rps 223. Ich danke der Bibliothek für die freundliche Publikationsgenehmigung. Der frühere Name der Bibliothek ist Wojewódzka i Miejska Biblioteka Publiczna im Stanislawa Staszica w Szczecinie.

5 Archiv der Humboldt-Universität Berlin. Album der Philosophischen Fakultät, 1. bis 47. Rektorat (1810-1857): Nr. 858, 17. Rektorat.

6 Archiv der Humboldt-Universität Berlin. Exmatrikel: AZ 1830, vol. LXXII, Bl. 157V-161R Vgl. Schubring 1996: 61.

7 Die staatliche Konzeption von Religionsunterricht beruhte also auf der rationalistischen Theologie. Prüfer Graßmanns in Religion war Friedrich Brescius, Generalsuperintendent der Niederlausitz und Konsistorialrat in Berlin (Handbuch 1831, 227). Brescius (1766-1842) war ein Praktiker; in mehreren Schriften kämpfte er „,vom Standpunkte des biblischen Supernaturalismus gegen die seichte Aufklärung jener Tage an“ (Allgemeine Deutsche Biographie, Bd. 3, 1876: 316).

8 Geheimes Staatsarchiv Preußischer Kulturbesitz Berlin. Akten des ehemaligen Preußischen Kultusministeriums, Rep. 76 VI, Sect. 14, x, Nr. 3, vol. II: Die wissenschaftliche Prüfungskommission zu Berlin, fol. 113.

9 Am Ende der Abschrift hat Eggebrecht notiert: „Die roten Anstriche und Änderungen entsprechen den mit roter Tinte gemachten Anstrichen und Verbesserungen von der Hand des Prüfungskommissars im Original“. Die Wiedergabe hier gibt die korrigierte Endversion. Signatur für beide Lebensläufe: siehe oben. Ich danke Claus von Bormann für die Übersetzung des Anfangs- und Schlussteils (ab der Rückkehr nach Stettin) und Klaus Schubring für die Übersetzung der mittleren Teile. Die Referate von Engel sind kursiv gesetzt.

10 Es muss offenbar "cursum“ heißen.

11 Es muss offenbar "desiderem“ heißen.

12 Vergleiche hierzu den weitgehend parallelen Bericht im deutschen Lebenslauf, Erster Abschnitt.

13 Vergleiche den Text im deutschen Lebenslauf von 1855.

14 Es muss offenbar "molesti“ heißen.

15 Trotz der genauen Korrekturlesung liegt hier ein Lesefehler vor; Engel schreibt hier ,laudem".

16 Es muss offenbar „praesertim“ heißen.

17 Es muss offenbar "finirem“ heißen.

18 Der die Latinität lobende Zusatz stammt vom Vorsitzenden der Prüfungskommission, Georg G. S. Köpke, Direktor des Gymnasiums zum Grauen Kloster. Auf dem Vorblatt mit der Überschrift hatte Köpke notiert: „Zur Zirkulation an die Mitglieder der K. Wiss. Prüf.-Kommission. Mündliches Examen d 17 Dezember 1831“. Nur der Mathematik-Prüfer Otto Schulz hat diesen Umlauf abgezeichnet: „legi“ Schulz 10.12.

19 Die Angabe in Klammern ist ein handschriftlicher Zusatz, offenbar vom Abschreiber aufgrund anderer Angaben in der Prüfungsakte gemacht.

20 Hier liegt vielleicht ein Übertragungsfehler vor: „,noch“ anstatt „,nicht“. 


\section{Literatur}

Engel, Friedrich, 1911. Grassmanns Leben. Nebst einem Verzeichnisse der von Grassmann veröffentlichten Schriften und einer Übersicht des handschriftlichen Nachlasses. Leipzig: Teubner.

Fries, Jacob Friedrich, 1822. Die mathematische Naturphilosophie, nach philosophischer Methode bearbeitet. Heidelberg: C. F. Winter.

Graßmann, Hermann, 1894. Die Ausdehnungslehre von 1844 und die geometrische Analyse. Leipzig: Teubner. [Gesammelte mathematische und physikalische Werke, Bd. 1, 1.].

Graßmann, Justus, 1827. Ueber den Begriff und Umfang der reinen Zahlenlehre. Schulprogramm Marien-Gymnasium Stettin. Stettin.

Greschat, Martin, 1997. Christentumsgeschichte II. Von der Reformation bis zur Gegenwart. Stuttgart: Kohlhammer.

Handbuch über den Preussischen Hof und Staat für das Jahr 1831. Berlin: von Decker.

Jüngel, Eberhard, 2004. Schleiermacher. In: Hans Dieter Betz, Hg. Religion in Geschichte und Gegenwart. Handwörterbuch für Theologie und Religionswissenschaft, Bd. 7. Tübingen: Mohr, Sp. 904-919 [4., völlig neu bearbeitete Aufl.].

Lewis, Albert C., 1977. Hermann Grassmann's 1844 Ausdehnungslehre and Schleiermacher's Dialektik. Annals of Science, 34, 103-162.

Nowak, Kurt, 2001. Schleiermacher. Leben, Werk und Wirkung. Göttingen: Vandenhoeck \& Ruprecht.

Das Reglement vom 20. April 1831 für die Prüfungen der Candidaten des höheren Schulamts in Preußen, mit den späteren Erläuterungen, Abänderungen und Erweiterungen. Berlin: Enslin, 1865. [LPO].

Petsche, Hans-Joachim, 2006. Graßmann. Basel: Birkhäuser [=Vita Mathematica, 13].

Röd, Wolfgang, 1974. Dialektische Philosophie der Neuzeit. Bd. 1: Von Kant bis Hegel. München: Beck.

Schlegel, Victor, 1878. Hermann Grassmann: sein Leben und seine Werke. Leipzig: Brockhaus.

Schleiermacher, Friedrich Daniel, 2003 [1830/1831]. Der christliche Glaube nach den Grundsätzen der evangelischen Kirche im Zusammenhange dargestellt. Zweite Auflage, Teilband 1 und 2. Berlin: de Gruyter [=Kritische Gesamtausgabe/Abt. 1, Schriften und Entwürfe, 13].

Scholz, Erhard,. 1996. The influence of Justus Grassmann's crystallographic works on Hermann Grassmann. In: Gert Schubring, Hg., Hermann Günther Graßmann (1809-1877): Visionary Mathematician, Scientist and Neohumanist Scholar. Papers from a Sesquicentennial Conference. Dordrecht u.a.: Kluwer, 37-45.

Schubring, Gert, 1990. Das mathematisch-Unendliche bei J. F. Fries. In: Gert König, Hg., Konzepte des mathematisch Unendlichen im 19. Jahrhundert. Göttingen: Vandenhoeck u. Ruprecht, 152-164.

Schubring, Gert, [1983] 1991. Die Entstehung des Mathematiklehrerberufs im 19. Jahrhundert. Studien und Materialien zum Prozeß der Professionalisierung in Preußen (1810-1870). Zweite, korrigierte und ergänzte Aufl. Weinheim: Deutscher Studien Verlag.

Schubring, Gert, 1996. The Cooperation between Hermann and Robert Grassmann on the Foundations of Mathematics. In: Gert Schubring, Hg., Hermann Günther Graßmann (1809-1877): Visionary Mathematician, Scientist and Neohumanist Scholar. Papers from a Sesquicentennial Conference. Dordrecht u.a.: Kluwer, 59-70.

Schubring, Gert, 2003. Il calcolo vettoriale di Grassmann. In Sandro Petruccioli, Hg., Storia della scienza, Bd. 7: L'Ottocento. Roma: Istituto dell'Enciclopedia Italiana, 147-149. 
Schubring, Gert/Freguglia, Paolo, 2004. Il calcolo geometrico. In: Sandro Petruccioli, Hg. Storia della scienza, Bd. 8: 1870-1950. Roma: Istituto dell'Enciclopedia Italiana, 88-92.

Troeltsch, Ernst, 1910. Gnade Gottes, III: Dogmatisch. In: Friedrich Michael Schiele, Hg., Die Religion in Geschichte und Gegenwart. Bd. 2. Tübingen: Mohr, Sp. 1470-1474.

Gert Schubring

Mathematics Department,

Universidade Federal do Rio de Janeiro,

Av. Brig. Trompowski,

Rio de Janeiro, RJ, Brazil

E-Mail: gert.schubring@uni-bielefeld.de 